\title{
Climatological Features of the Weakly and Very Stably Stratified Nocturnal Boundary Layers. Part III: The Structure of Meteorological State Variables in Persistent Regime Nights and across Regime Transitions
}

\author{
CARSTEN ABRAHAm AND ADAm H. MONAHAN \\ School of Earth and Ocean Sciences, University of Victoria, Victoria, British Columbia, Canada
}

(Manuscript received 6 September 2018, in final form 9 August 2019)

\begin{abstract}
The evolution of profiles of meteorological state variables during nights with and without transitions in the nocturnal stably stratified boundary layer (SBL) between weakly stable (wSBL) and very stable (vSBL) regimes, as classified by a hidden Markov model, is examined at nine different tower sites. During wSBL-tovSBL transitions, inversion strengths increase, near-surface winds decelerate, and atmospheric layers vertically decouple. Turbulence kinetic energy (TKE) steadily decreases before wSBL-to-vSBL transitions and fluctuations of the vertical velocity become weak. In contrast to land-based sites where wSBL-to-vSBL transitions are normally caused by surface cooling, at sea-based stations the transitions generally are initiated by advection of warm air aloft. The vSBL-to-wSBL transition is characterized by a fast breakdown of the inversion strength, acceleration of wind profiles, and a restored vertical coupling of the atmospheric flow. TKE recovers on time scales of minutes first in atmospheric levels between 50 and $100 \mathrm{~m}$. Profiles of state variables for the two different regimes during very persistent nights (nights without SBL regime transitions) are clearly separated and similar to structures during nights with transitions away from transition times. During very persistent nights the wind conditions stay relatively steady. Similarly, the temperature is steady after an initial adjustment time at sunset (wSBL) or shortly after sunset (vSBL). Even though nights with and without transitions are a common feature of the SBL, there is no clear indicator in Reynolds-averaged mean variables that distinguishes very persistent nights from nights with transitions.
\end{abstract}

\section{Introduction}

On the basis of Reynolds-averaged mean data, observations of the nocturnal stably stratified boundary layer (SBL) are often classified into two distinct regimes (e.g., Mahrt 1998a; Acevedo and Fitzjarrald 2003; Mahrt 2014; van Hooijdonk et al. 2015; Monahan et al. 2015; Vercauteren and Klein 2015; Acevedo et al. 2016; Vignon et al. 2017b; Abraham and Monahan 2019a,b, hereafter AM19a and AM19b). One regime is referred to as the weakly SBL (wSBL), characterized by weak stratification, strong winds and shears, which produce sufficient turbulence kinetic energy (TKE) to sustain continuous turbulence and vertical mixing despite the stable stratification (e.g., van de Wiel et al. 2012a). This regime conforms to the classical understanding of turbulence in the atmospheric boundary layer with turbulent quantities decreasing with height and near-surface profiles, which are well described by Monin-Obukhov

\footnotetext{
Corresponding author: Carsten Abraham, abrahamc@uvic.ca
}

similarity theory (MOST) in horizontally homogeneous conditions (e.g., Sorbjan 1986; Mahrt 1998a,b, 2014; Pahlow et al. 2001; Grachev et al. 2005, 2013). The other regime, referred to as the very stable SBL (vSBL), is characterized by weak and intermittent turbulence, strong stratification, and low wind speeds. In this regime turbulence profiles can decouple from the surface (Banta et al. 2007) and MOST breaks down (e.g., Derbyshire 1999; Banta et al. 2007; Williams et al. 2013; Mahrt 2011; Optis et al. 2016). These regimes and transitions between them are poorly represented in weather and climate models, due both to coarse resolution (vertical and horizontal) and to an imperfect understanding of all the diverse physical processes governing the SBL (e.g., Holtslag et al. 2013; Mahrt 2014). In this study the climatological evolution and structure of meteorological state variables during times of transitions between these two SBL regime states are investigated across different tower sites, and compared to state-variable structures in nights without SBL regime transitions. We use the term "climatological" in this context to refer to 
the characterization of statistics from many years of observations.

Transitions between these two regimes result from different physical mechanisms. Over land and ice-snow surfaces, the wSBL-to-vSBL transition (which for simplicity we refer to as the collapse of turbulence although intermittent turbulence events are a feature of the vSBL) is normally caused by radiative cooling at the surface increasing the inversion strength and suppressing turbulent vertical fluxes of momentum and heat. This process is relatively well understood and can be explained by conceptual models (van de Wiel et al. 2007, 2017; Holdsworth et al. 2016) or in direct numerical simulations of stratified channel flows (Donda et al. 2015; van Hooijdonk et al. 2017) or atmospheric boundary layers (e.g., Flores and Riley 2011; Ansorge and Mellado 2014). Turbulence collapse can also occur when strongly stable stratification is produced by the advection of warm air over a cold surface (Dörenkämper et al. 2015).

The reverse vSBL-to-wSBL transition (which for simplicity we denote as the recovery of turbulence) is less well understood. One mechanism by which turbulence recovers includes the gradual buildup of shear resulting in instabilities. Another potential class of processes initiating these transitions is associated with intermittent turbulence events (Durst 1933; Gifford 1952; Kondo et al. 1978; Nappo 1991; van de Wiel et al. 2002a,b, 2003; Acevedo and Fitzjarrald 2003; Nakamura and Mahrt 2005; Ohya et al. 2008; White 2009; Baklanov et al. 2011; Medeiros and Fitzjarrald 2014; Mahrt et al. 2012; Mahrt 2014; Vercauteren and Klein 2015), which have been found to dominate the turbulent transport in vSBL conditions (Nappo 1991; Coulter and Doran 2002; Doran 2004; Basu et al. 2006; Acevedo et al. 2006; Williams et al. 2013). The turbulence intensities can be strong enough to break down the inversion, resulting in a transition to the wSBL. The recovery of turbulence also leads to a deeper planetary boundary layer.

Intermittent turbulence arises from a range of different phenomena such as breaking gravity waves or solitary waves (Mauritsen and Svensson 2007; Sun et al. 2012), density currents (Sun et al. 2002), microfronts (Mahrt 2010), Kelvin-Helmholtz instabilities interacting with the turbulent mixing (Blumen et al. 2001; Newsom and Banta 2003; Sun et al. 2012), or shear instabilities induced from internal wave propagation (Sun et al. 2004; Zilitinkevich et al. 2008; Sun et al. 2015). It has even been suggested from direct numerical simulations that intermittency can arise as an intrinsic mode of the nonlinear equations in the absence of external perturbations of the mean flow (Ansorge and Mellado 2014). Regime transitions can also be associated with a change in low-level cloud coverage (AM19b).
As demonstrated in the first part of this study (AM19a), a hidden Markov model (HMM) analysis of the Reynolds-averaged mean dry static stratification, verticalmean wind speed, and scalar wind speed shear between the surface and aloft characterizes the two-regime behavior of the SBL and allows for the systematic study of the climatological features of SBL regime transitions. The existence of these two distinct regimes is found to be generic across nine tower sites differing in surface type, climate region, and variability of surrounding roughness or topographic complexity. The HMM is of particular utility for separating the two regimes under low wind speed and with weak stratification conditions. Regimes diagnosed by the HMM analyses of Reynolds-averaged mean variables are also found to distinguish turbulence intensities into physically meaningful clusters.

The HMM is a statistical approach that models an unobserved (therefore "hidden") Markov chain on the basis of a set of observable state variables. In addition to determining parametric probability density functions (pdfs) of the input variables conditional on each regime, the HMM classifies each data point into one of the regimes (thereby generating a time series of regime occupation). This HMM estimation of the regime occupation sequence is not based just on the instantaneous state of the input variables but takes the history of the process into account. In the case of the SBL the number of predefined regimes is chosen to be two, based on visual inspection of the data scatter and a detailed sensitivity analysis (AM19a). A detailed descriptions of the HMM algorithm is presented in Rabiner (1989), and details of the application to the nine tower sites considered in this study are given in AM19a.

Although many different classification schemes for the SBL have been proposed (Acevedo and Fitzjarrald 2003; Acevedo et al. 2016; Grachev et al. 2005, 2008; Sun et al. 2012; van de Wiel et al. 2012a,b, 2017; Mahrt 2014; Ansorge and Mellado 2014; Vercauteren and Klein 2015) the HMM analysis of the Reynolds-averaged mean data allows only for a robust classification across different tower sites into two regimes (AM19a). Most classification schemes involving more than two regimes are based on the details of the turbulent and submesoscale variability of the flow, and are therefore not distinguished by the long-term Reynolds-averaged data we consider to investigate climatological features of the SBL regimes. A detailed discussion of different SBL classification schemes is presented in AM19a.

Regime sequences estimated from the HMM have been used to determine climatological regime occupations of nights with and without regime transitions (AM19b). We refer to the latter as "very persistent" nights. Both types of nights are a common feature across 
different tower sites with very persistent nights occurring more likely in homogeneous surroundings and in particular at sea-based stations. While the occurrence of very persistent nights is seasonally dependent (with larger frequency of very persistent wSBL in winter and of very persistent vSBL in summer), the statistics of transitions do not display strong seasonal dependence. As nights with and without transitions are common, a comprehensive climatological study of SBL regimes requires consideration of both classes of night.

Many previous studies have used case studies based on data from field campaigns to study the different wind speed, temperature, TKE, and turbulent flux profiles in the SBL regimes. In particular, the CASES-99 field campaign has provided valuable information for contrasting the state-variable conditions in the two SBL regimes and in approach to a transition (e.g., Blumen et al. 2001; Sun et al. 2002, 2004, 2012, 2015; Banta et al. 2006). Other case studies have found very similar behavior of regime transitions between wSBL and vSBL conditions (e.g., Grant 1997; Lundquist 2003; White 2009; Vignon et al. 2017b; Deb Burman et al. 2018; Acevedo et al. 2019; Yus-Díez et al. 2019). To our understanding, the longest-term analysis of the SBL is the Fluxes over Snow-Covered Surfaces II field campaign with measurements for about half a year (e.g., Mahrt and Vickers 2006; Acevedo et al. 2016). However, to the best of our knowledge, a comprehensive climatological behavior over many nights and a range of different spatial locations has not been conducted yet. Such climatological structures lead to a better understanding of robust common features of SBL regime dynamics and how these are modulated by sitespecific characteristics than case studies or field campaigns can offer. The climatological structures of the SBL regimes at times of regime transitions and in persistent regime condition are also important for the development of parameterizations of the effect of SBL regime dynamics in weather and climate models. In a related study we develop a prototype of an explicitly stochastic version of such parameterization (Abraham et al. 2019).

In the present study we investigate such climatological profiles of Reynolds-averaged mean meteorological state variables across times of transitions between SBL regimes and compare them across different tower sites. We then compare and contrast these profiles to climatological features of very persistent nights. This study is organized as follows. We briefly review the data to be used in section 2 . Results are described in section 3 followed by conclusions in section 4.

\section{Data}

The observational data used in this study are discussed in detail in AM19a. We present here a short summary of the data. Observational datasets from nine different research towers measuring standard Reynolds-averaged meteorological state variables with a time resolution of $30 \mathrm{~min}$ or finer are considered (Table 1). Observational levels used to characterize stratification and scalar wind shear for use in the HMM analyses are identified in boldface font in this table. Substantial differences among the nine experimental sites exist in terms of their surface conditions, surrounding topography, and their meteorological setting. As a simple classification scheme, we distinguish between land-based, glacial-based, and sea-based stations.

The land-based stations can be further clustered into different subsets. Both the Cabauw and Hamburg towers lie in flat, humid, grassland areas, although the Hamburg tower is affected by the large metropolitan area of Hamburg. The Karlsruhe tower is located in the Rhine valley, a rather hilly, forested area, north of the urban center and due to the local flow patterns often in the lee of the city. The American sites, Boulder and Los Alamos, are located in more arid areas than the other stations and are strongly affected by the surrounding topography of the Rocky Mountains.

The Dome C observatory, the single glacial-based station, is located in the interior of Antarctica and influenced by completely different surface conditions including high albedo and low roughness length. Measurement heights at this station are variable due to changing snow depths; the values quoted in Table 1 are averages over the 5 years considered.

The sea-based stations are the offshore research platforms Forschungsplattform in Nord- und Ostsee (FINO), which are located in the North (FINO-1 and FINO-3) and Baltic Seas (FINO-2). These sites are characterized by relatively homogeneous surroundings and a large surface heat capacity. At the FINO towers we exclude nights with statically unstable conditions (defined as nights with two or more unstable data points in a night) as under these conditions the wind speed measurements have been found to be unreliable (Westerhellweg and Neumann 2012). Furthermore, at FINO-1 nights with primary wind directions between $280^{\circ}$ and $340^{\circ}$ are excluded due to mast interference effects. At the other stations such an exclusion is not necessary as three wind measurements with $120^{\circ}$ separation are taken at each level.

At those sites where the data are available to do so (Cabauw, Hamburg, Los Alamos), we define the beginning of the night as the time the net radiative surface 
TABLE 1. Information about the different meteorological tower sites and their measurement heights sorted alphabetically from landbased, to glacial-based, to sea-based sites. Detailed information about the sites is presented in the cited references. The data are Reynoldsaveraged (Avg) mean values of wind speed $W$, wind direction $\alpha$, temperature $T$, and pressure $P$. Heights indicated in boldface numbers denote the altitudes of the observations entering the HMM considered in this study (AM19a).

\begin{tabular}{|c|c|c|c|c|c|c|}
\hline Institute & References & Geolocation & $\begin{array}{l}\text { Time } \\
\text { period }\end{array}$ & Data & $\begin{array}{c}\text { Avg } \\
(\mathrm{min})\end{array}$ & Measurement heights (m) \\
\hline \multicolumn{7}{|c|}{ Land-based tower sites } \\
\hline $\begin{array}{l}\text { Boulder Atmospheric } \\
\text { Observatory (BAO), } \\
\text { Boulder, Colorado }\end{array}$ & $\begin{array}{l}\text { Kaimal and Gaynor } \\
\quad \text { (1983), Blumen } \\
\text { (1984) }\end{array}$ & $\begin{array}{c}40.0500^{\circ} \mathrm{N}, 105.0038^{\circ} \mathrm{W} \\
1584 \mathrm{~m}\end{array}$ & $2008-15$ & $\begin{array}{l}P \\
W \\
\alpha \\
T\end{array}$ & $\begin{array}{l}10 \\
10 \\
10 \\
10\end{array}$ & $\begin{array}{c}\text { Surface } \\
\mathbf{1 0}, \mathbf{1 0 0}, 300 \\
10,100,300 \\
\mathbf{1 0}, \mathbf{1 0 0}, 300\end{array}$ \\
\hline $\begin{array}{l}\text { Royal Netherlands } \\
\text { Meteorological } \\
\text { Institute (KNMI), } \\
\text { Cabauw, Netherlands }\end{array}$ & $\begin{array}{l}\text { Van Ulden and } \\
\text { Wieringa (1996) }\end{array}$ & $\begin{array}{c}51.9700^{\circ} \mathrm{N}, 4.9262^{\circ} \mathrm{E} \\
-0.7 \mathrm{~m}\end{array}$ & $2001-15$ & $\begin{array}{l}P \\
W \\
\alpha \\
T\end{array}$ & $\begin{array}{l}10 \\
10 \\
10 \\
10\end{array}$ & $\begin{array}{c}\text { Surface } \\
\mathbf{1 0}, 20,40,80,140, \mathbf{2 0 0} \\
10,20,40,80,140,200 \\
\text { 2, } 10,20,40,80,140, \mathbf{2 0 0}\end{array}$ \\
\hline $\begin{array}{l}\text { Meteorologisches } \\
\text { Institut der Universität } \\
\text { Hamburg (MI), } \\
\text { Hamburg, Germany }\end{array}$ & $\begin{array}{l}\text { Brümmer et al. } \\
\text { (2012), Floors } \\
\text { et al. (2015), } \\
\text { Gryning et al. } \\
\text { (2016) }\end{array}$ & $\begin{array}{c}53.5192^{\circ} \mathrm{N}, 10.1051^{\circ} \mathrm{E} \\
0.3 \mathrm{~m}\end{array}$ & $2005-15$ & $\begin{array}{l}P \\
W \\
\alpha \\
T\end{array}$ & $\begin{array}{l}1 \\
1 \\
1 \\
1\end{array}$ & $\begin{array}{c}2 \\
\mathbf{1 0}, 50,110,175, \mathbf{2 5 0}, 280 \\
10,50,110,175,250,280 \\
\mathbf{2}, 10,50,110,175, \mathbf{2 5 0}, 280\end{array}$ \\
\hline $\begin{array}{l}\text { Karlsruher Institut für } \\
\text { Technologie (KIT) } \\
\text { Karlsruhe, Germany }\end{array}$ & $\begin{array}{l}\text { Kalthoff and Vogel } \\
\text { (1992), Wenzel } \\
\text { et al. (1997), } \\
\text { Barthlott et al. } \\
\text { (2003), Kohler } \\
\text { et al. (2018) }\end{array}$ & $\begin{array}{c}49.0925^{\circ} \mathrm{N}, 8.4258^{\circ} \mathrm{E} \\
110.4 \mathrm{~m}\end{array}$ & $2003-13$ & $\begin{array}{l}P \\
W \\
\alpha \\
T\end{array}$ & $\begin{array}{l}10 \\
10 \\
10 \\
10\end{array}$ & $\begin{array}{c}\text { Surface } \\
\mathbf{2}, 20,30,40,50,60,80,100,130 \\
160, \mathbf{2 0 0} \\
40,100,200 \\
\mathbf{2}, 10,30,60,100,130,160, \mathbf{2 0 0}\end{array}$ \\
\hline $\begin{array}{l}\text { Los Alamos National } \\
\text { Laboratory (LANL), } \\
\text { Los Alamos, New } \\
\text { Mexico }\end{array}$ & $\begin{array}{l}\text { Bowen et al. (2000), } \\
\text { Rishel et al. (2003) }\end{array}$ & $\begin{array}{c}35.8614^{\circ} \mathrm{N}, 106.3196^{\circ} \mathrm{W} \\
2263 \mathrm{~m}\end{array}$ & $1995-2015$ & $\begin{array}{l}P \\
W \\
\alpha \\
T\end{array}$ & $\begin{array}{l}15 \\
15 \\
15 \\
15\end{array}$ & $\begin{array}{c}1.2 \\
\mathbf{1 1 . 5}, 23,46, \mathbf{9 2} \\
11.5,23,46,92 \\
\mathbf{1 . 2}, 11.5,23,46, \mathbf{9 2}\end{array}$ \\
\hline $\begin{array}{l}\text { Institut Polaire Français } \\
\text { Paul-Émile Victor } \\
\text { (IPEV), and Programma } \\
\text { Nazionale Ricerche in } \\
\text { Antartide (PNRA), } \\
\text { Dome C, Antarctica }\end{array}$ & $\begin{array}{l}\text { Genthon et al. (2010, } \\
\text { 2013), Vignon } \\
\text { et al. (2017a,b) }\end{array}$ & $\begin{array}{l}\text { Glacial-based towe } \\
75.1000^{\circ} \mathrm{S}, 123.3000^{\circ} \mathrm{E} \\
3233 \mathrm{~m}\end{array}$ & 2011-16 & $\begin{array}{l}P \\
W \\
\alpha \\
T\end{array}$ & $\begin{array}{l}30 \\
30 \\
30 \\
30\end{array}$ & $\begin{array}{c}0.7 \\
\mathbf{1 . 3}, 2.3,3.5, \mathbf{9}, 18.2,25.6,32.9,41.3 \\
1.3,2.3,3.5,9,18.2,25.6,32.9,41.3 \\
\mathbf{0 . 9}, 1.9,2.9, \mathbf{1 0 . 3}, 17.7,25,32.4,41.6\end{array}$ \\
\hline \multicolumn{7}{|c|}{ Sea-based tower sites } \\
\hline $\begin{array}{l}\text { Forschungs- und } \\
\text { Entwicklungszentrum } \\
\text { Fachhochschule Kiel } \\
\text { GmbH, FINO-1, } \\
\text { Germany }\end{array}$ & $\begin{array}{r}\text { Beeken et al. (2008), } \\
\text { Fischer et al. (2012) }\end{array}$ & $\begin{array}{c}54.0140^{\circ} \mathrm{N}, 6.5876^{\circ} \mathrm{E} \\
0 \mathrm{~m}\end{array}$ & $2004-15$ & $\begin{array}{l}P \\
W \\
\alpha \\
T\end{array}$ & $\begin{array}{l}10 \\
10 \\
10 \\
10\end{array}$ & $\begin{array}{c}20,90 \\
\mathbf{3 3}, 40,50,60,70,80,90, \mathbf{1 0 0} \\
33,40,50,60,70,80,90 \\
\mathbf{3 0}, 40,50,70, \mathbf{1 0 0}\end{array}$ \\
\hline $\begin{array}{l}\text { Forschungs- und } \\
\text { Entwicklungszentrum } \\
\text { Fachhochschule Kiel } \\
\text { GmbH, FINO-2, } \\
\text { Germany }\end{array}$ & $\begin{array}{l}\text { Dörenkämper et al. } \\
\text { (2015) }\end{array}$ & $\begin{array}{c}55.0069^{\circ} \mathrm{N}, 13.1542^{\circ} \mathrm{E} \\
0 \mathrm{~m}\end{array}$ & $2008-15$ & $\begin{array}{l}P \\
W \\
\alpha \\
T\end{array}$ & $\begin{array}{l}10 \\
10 \\
10 \\
10\end{array}$ & $\begin{array}{c}30,90 \\
\mathbf{3 2}, 42,52,62,72,82,92, \mathbf{1 0 2} \\
32,42,52,62,72,82,92 \\
\mathbf{3 0}, 40,50,70, \mathbf{9 9}\end{array}$ \\
\hline $\begin{array}{l}\text { Forschungs- und } \\
\text { Entwicklungszentrum } \\
\text { Fachhochschule Kiel } \\
\text { GmbH, FINO-3, } \\
\text { Germany }\end{array}$ & Fischer et al. (2012) & $\begin{array}{c}55.1950^{\circ} \mathrm{N}, 7.1583^{\circ} \mathrm{E}, \\
0 \mathrm{~m}\end{array}$ & $2010-15$ & $\begin{array}{l}P \\
W \\
\alpha \\
T\end{array}$ & $\begin{array}{l}10 \\
10 \\
10 \\
10\end{array}$ & $\begin{array}{c}23,95 \\
\mathbf{3 0}, 40,50,60,70,80,90, \mathbf{1 0 0} \\
29,60,100 \\
\mathbf{2 9}, 55, \mathbf{9 5}\end{array}$ \\
\hline
\end{tabular}

flux $Q_{N}$ [sum of downwelling and upwelling longwave radiation (LWR) and shortwave radiation (SWR)] becomes negative. By this definition, the beginning of the night can be earlier than the actual sunset or the time that SWR becomes zero. At observational sites where radiative fluxes are not available, we define nighttime as starting $2 \mathrm{~h}$ before actual sunset given by the date and geographical location. Due to its high-latitude location the periods analyzed at Dome $\mathrm{C}$ include long-lasting polar nights. 
TABLE 2. Information about the turbulence variables measured at the weather tower sites and their measurement heights. The available data are variances in the $x$ direction $\sigma_{u}, y$ direction $\sigma_{v}$, and $z$ direction $\sigma_{w}$, as well as longitudinal and lateral components of the wind stress $\left(\overline{u^{\prime} w^{\prime}}\right.$ and $\overline{v^{\prime} w^{\prime}}$, respectively), and kinematic heat flux $\overline{w^{\prime} T^{\prime}}$.

\begin{tabular}{|c|c|c|c|c|}
\hline Institute & Time period & Data & $\operatorname{Avg}(\min )$ & Measurement heights (m) \\
\hline \multirow{6}{*}{$\begin{array}{l}\text { Royal Netherlands Meteorological Institute } \\
\text { (KNMI), Cabauw, Netherlands }\end{array}$} & \multirow[t]{6}{*}{ July 2007-June 2008} & $\sigma_{u}$ & 10 & $5,60,100,180$ \\
\hline & & $\sigma_{v}$ & 10 & $5,60,100,180$ \\
\hline & & $\sigma_{w}$ & 10 & $5,60,100,180$ \\
\hline & & $\overline{u^{\prime} w^{\prime}}$ & 10 & $5,60,100,180$ \\
\hline & & $\overline{v^{\prime} w^{\prime}}$ & 10 & $5,60,100,180$ \\
\hline & & $\overline{w^{\prime} T^{\prime}}$ & 10 & $5,60,100,180$ \\
\hline \multirow{6}{*}{$\begin{array}{l}\text { Meteorologisches Institut der Universität } \\
\text { Hamburg (MI), Hamburg, Germany }\end{array}$} & \multirow[t]{6}{*}{$2005-15$} & $\sigma_{u}$ & 1 & $10,50,110,175,250,280$ \\
\hline & & $\sigma_{v}$ & 1 & $10,50,110,175,250,280$ \\
\hline & & $\sigma_{w}$ & 1 & $10,50,110,175,250,280$ \\
\hline & & $\overline{u^{\prime} w^{\prime}}$ & 1 & $10,50,110,175,250,280$ \\
\hline & & $\overline{v^{\prime} w^{\prime}}$ & 1 & $10,50,110,175,250,280$ \\
\hline & & $\overline{w^{\prime} T^{\prime}}$ & 1 & $10,50,110,175,250,280$ \\
\hline \multirow{2}{*}{$\begin{array}{l}\text { Los Alamos National Laboratory (LANL), } \\
\text { Los Alamos, New Mexico }\end{array}$} & \multirow[t]{2}{*}{ 1995-2015 } & $\sqrt{\sigma_{u}^{2}+\sigma_{v}^{2}}$ & 15 & $11.5,23,46,92$ \\
\hline & & $\sigma_{w}$ & 15 & $11.5,23,46,92$ \\
\hline
\end{tabular}

Observations of Reynolds-averaged turbulence state variables such as TKE and vertical fluxes were provided for towers in Cabauw, Hamburg, and Los Alamos (Table 2). At the Hamburg site we exclude turbulence data when the flow is from the north $\left(335^{\circ}-25^{\circ}\right)$ because of clear evidence of mast effects under very stable conditions. For the same reasons, we exclude turbulence data for wind directions between $280^{\circ}$ and $340^{\circ}$ at Cabauw.

To investigate directional wind shears in addition to vertical scalar shears, wind components across and along the wind at the highest observation height are defined as

$$
\begin{aligned}
& W_{h} \perp W_{h_{\max }}=W_{h} \sin \left(\alpha_{h_{\max }}-\alpha_{h}\right), \\
& W_{h} \| W_{h_{\max }}=W_{h} \cos \left(\alpha_{h_{\max }}-\alpha_{h}\right),
\end{aligned}
$$

where $W$ and $\alpha$ are, respectively, the wind speed and direction, and the subscripts $h$ and $h_{\max }$ denote, respectively, the observation height under consideration and the highest observation height of the tower. Defining the components along and across the flow at the highest measured altitude allows investigation of directional wind shear in the boundary layer, a measure of the coupling strength between the flow at the surface and aloft.

Static stabilities are calculated as the potential temperature $(\Theta)$ difference between two heights. Potential temperatures are calculated assuming hydrostatic equilibrium, an acceleration due to gravity of $9.81 \mathrm{~m} \mathrm{~s}^{-2}$, a specific heat capacity of $1005 \mathrm{~J} \mathrm{~kg}^{-1} \mathrm{~K}^{-1}$, and the specific gas constant of $287 \mathrm{~J} \mathrm{~kg}^{-1} \mathrm{~K}^{-1}$.

\section{Results}

The hidden state occupation sequence of the HMM analysis (the classification of each observational time step into one of the vSBL or wSBL; AM19a) allows for a systematic examination of the structure and timing of transitions. As discussed in AM19b the regime sequence also allows the identification of "very persistent" nights. First, we present composites of the evolution of Reynolds-averaged mean and turbulence intensities across transitions. We then examine the state-variable structures of very persistent wSBL and vSBL nights and compare their structures to those in times of SBL regime transitions.

\section{a. The structure of Reynolds-averaged mean state variables across times of transitions}

To systematically analyze the climatological features of changes in the structure of meteorological state variables at times of transitions we investigate composites of the evolution of these quantities. Such composites provide information about the average behavior during transitions across the different tower locations. The composites are centered on the times of transitions and extend $90 \mathrm{~min}$ before and after. For Reynolds-averaged mean state variables, composites computed from median values are much the same as those based on the means and so are not shown. Because they aggregate structures across many transitions, the composites do not distinguish differences between individual events, which may be important for a detailed physical understanding of a specific transition. Furthermore, different transitions might not be perfectly aligned, and abrupt changes may be somewhat smoothened, due to the reliance on time-averaged data. Our analysis of the climatological mean behavior is intended to highlight common features among transitions, and to allow comparison of these between different locations. 
Although the transition probabilities themselves depend on the time of the night (particularly the wSBL-tovSBL transition; AM19b), the transition composites are not qualitatively sensitive to the timing of transitions (not shown). This result indicates that special types of SBL regime transitions (for instance transitions induced by intermittent turbulence events) do not predominate in specific times of the night. Furthermore, specification of composites based on only first or subsequent transitions (transitions occurring after preceding turbulence collapses or recovery events) in a night does not qualitatively change the results of the composite analysis.

\section{1) LAND-BASED TOWER SITES}

Composite wind and stratification profiles (which include all state variables used in the HMM analyses) across times of transitions are qualitatively similar for all land-based tower sites (Fig. 1; note that the scale of the vertical axes differ between the different sites and that the stratification is calculated as the potential temperature difference between each height and the measurement nearest the surface).

With the exception of Hamburg and Karlsruhe, the near-surface wind speed decreases by about $2-3 \mathrm{~m} \mathrm{~s}^{-1}$ during the wSBL-to-vSBL transition (Fig. 1, first column). While the wind speed at Boulder and Los Alamos decreases substantially at all observed altitudes, at Cabauw, Hamburg, and Karlsruhe the wind speed aloft decreases moderately at the moment of the transition. After an initial deceleration of the whole wind profile, wind speeds aloft start to accelerate steadily about 20-30 min after the wSBL-to-vSBL transition, likely due to the development of a low-level jet. Only at Karlsruhe is no low-level-jet development evident.

As expected, the static stability increases during wSBL-to-vSBL transitions (Fig. 1, second column). At these land-based sites the transition starts from a nearly neutral to weakly stable stratification (at Boulder only in the bottom $100 \mathrm{~m}$ ). The stratification then begins to strengthen about $60-30 \mathrm{~min}$ before the moment of the wSBL-to-vSBL transition, and continues to increase gradually after the transition. At Los Alamos the stratification in the lowest $50 \mathrm{~m}$ becomes particularly strong. In the established vSBL the European sites have quite similar stratification strengths, somewhat weaker than at the North American sites. This result suggests the importance of the thermal conductivity of the surface, which was hypothesized as a controlling factor in the conceptual model of van de Wiel et al. (2017). At the American, more arid regions it is also evident that "steady state" in the vSBL is faster reached than in more humid regions possibly due to a lower thermal conductivity of drier regions.
The vSBL-to-wSBL transition shows a clear increase of wind speeds at all measurement levels (Fig. 1, third column). In particular, at Boulder and Los Alamos an increase of about $2-3 \mathrm{~m} \mathrm{~s}^{-1}$ is observed. At the European sites the increase is about $1-2 \mathrm{~m} \mathrm{~s}^{-1}$. The change in wind speed has the same sign at all measurement altitudes, suggesting that it results from the entrainment of highmomentum fluid from above the highest observational levels. Another possibility is that in a vertically coupled boundary layer the surface momentum flux is balanced across a deeper layer (making the vertical mean turbulent momentum flux convergence smaller) allowing the flow to accelerate (Samelson et al. 2006).

In contrast to the rather slow buildup of inversion strength at times of the wSBL-to-vSBL transition, the reverse transition happens rather abruptly, with the first evidence of changes occurring about 20-30 min before the transition (Fig. 1, fourth column). Across the landbased stations, the inversion strength is substantially decreased in the lower $100 \mathrm{~m}$. Shortly after the transition the stratification remains relatively steady, except at Los Alamos where the inversion recovers relatively quickly. This difference may result from the fact that the site is characterized by a low thermal conductivity and little cloud cover, encouraging radiative cooling at the surface (AM19b). Interestingly, at Boulder reduction in inversion strength is most prominent between about 50 and $150 \mathrm{~m}$.

Across all land-based sites composite stratification evolves gradually in wSBL-to-vSBL transitions due to the continuous surface cooling (caused by increasing nearsurface radiative flux divergence), which continuously strengthens the inversion. In fact, potential temperature profiles reveal the formation of cold-air pooling near the surface preceding the occurrence of wSBL-to-vSBL transitions (Fig. 2, first column). Deviations from the 180-min time mean show that the cooling at higher levels is substantially smaller than that at the surface (Fig. 2, second column). In the reverse transition, from the vSBL to the wSBL, the strongest changes in temperature appear aloft while surface temperatures change little or increase only slightly (Fig. 2, third and fourth columns). The temperature changes show the same overall cooling as the wSBL-to-vSBL transitions due to the continuous radiative cooling over the course of the night. However, the recovery of turbulence and the related increased mixing of fluid with higher potential temperature from aloft toward surface layers (and of cooler air from the surface to higher levels) leads to reduced cooling near the surface (or even an initial warming) and a more pronounced cooling aloft. Evidence of this mixing is the positive temperature anomaly in the period between about $10 \mathrm{~min}$ before and $30-40 \mathrm{~min}$ after the transition 
wSBL to vSBL transition
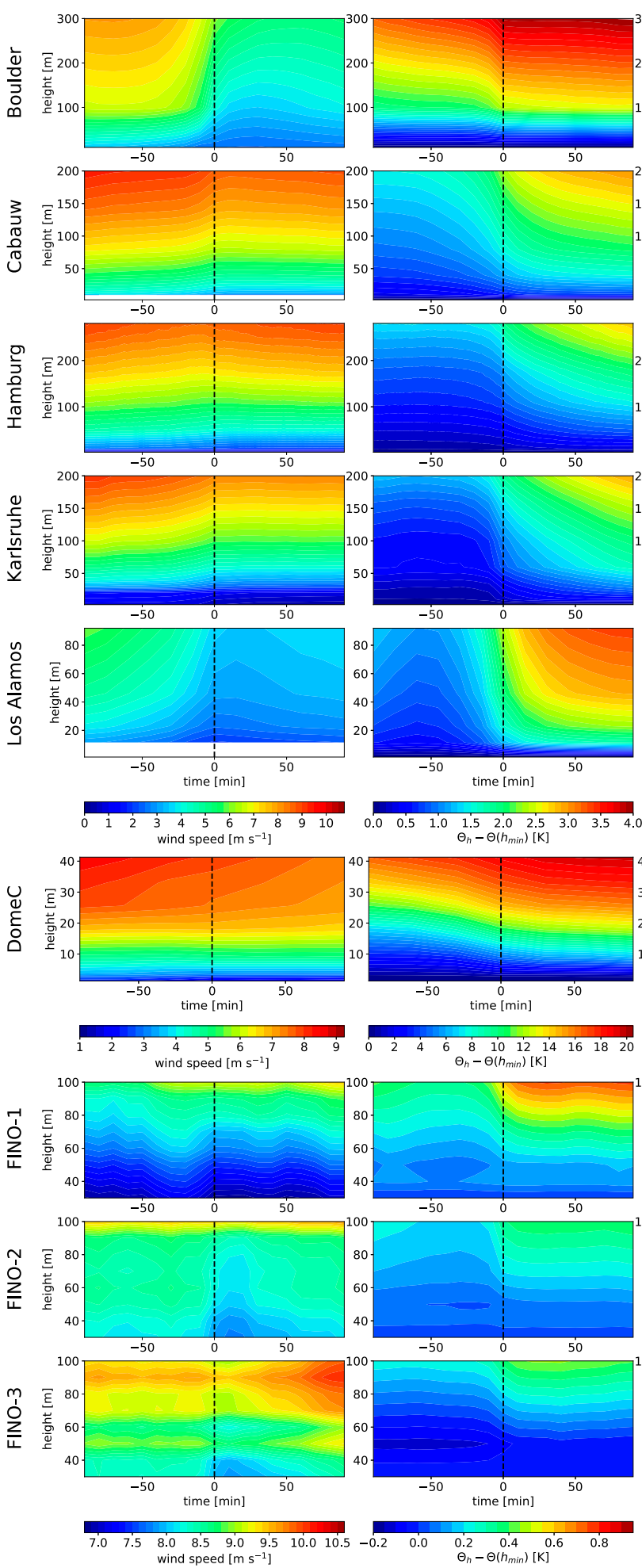

vSBL to wSBL transition
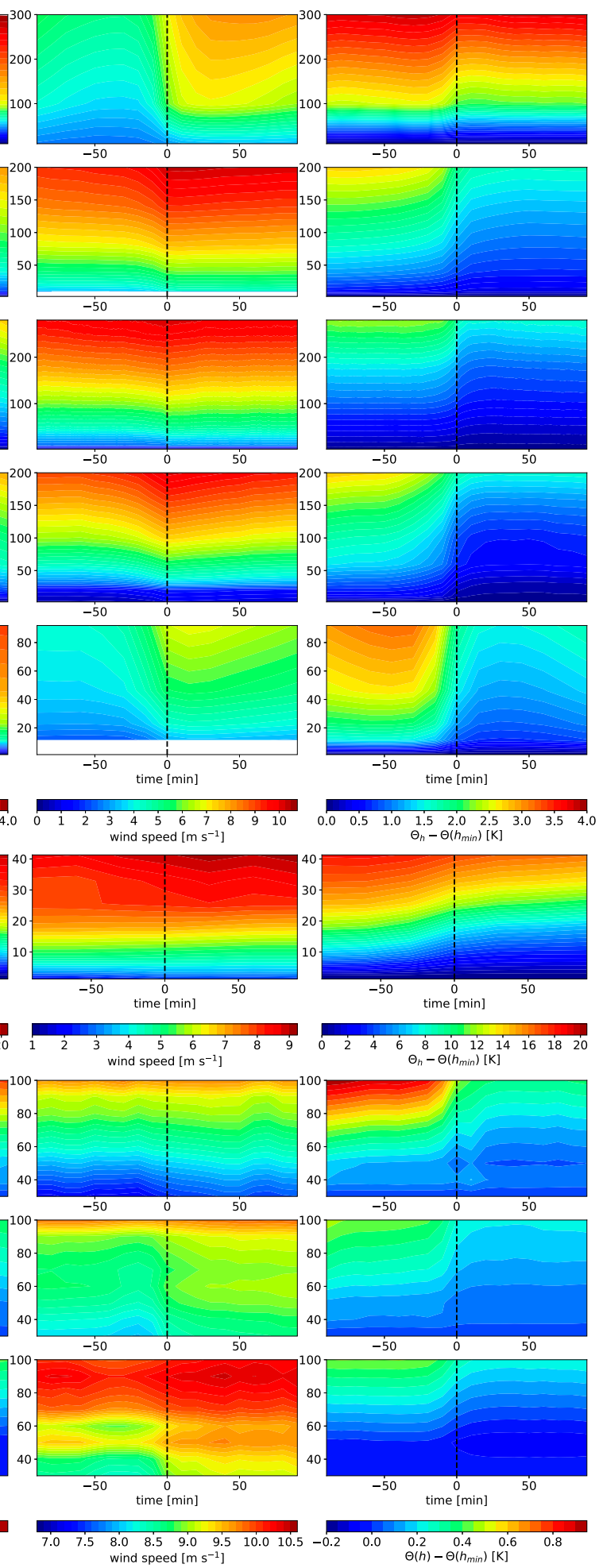

FIG. 1. Time evolution of the composite means of the (first and third columns) wind speed and (second and fourth columns) stratification profiles at the different tower sites during times of (first and second columns) turbulence collapse (wSBL-to-vSBL transition) and (third and fourth columns) turbulence recovery (vSBL-to-wSBL transition) as determined by the HMM analyses. The composites show the $90 \mathrm{~min}$ before and after the transitions at time $t=0$ (dashed reference line). 
wSBL to vSBL transition
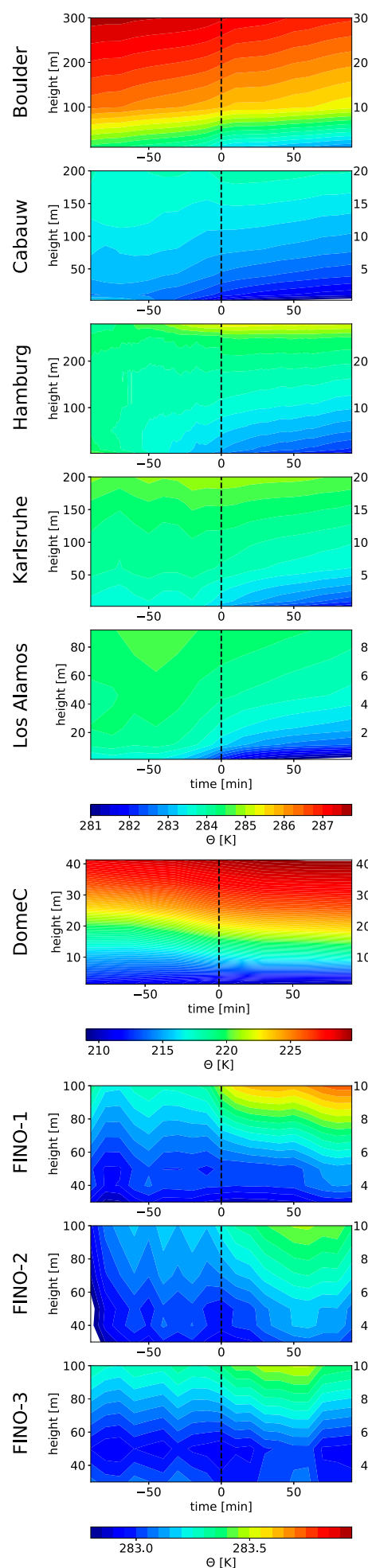
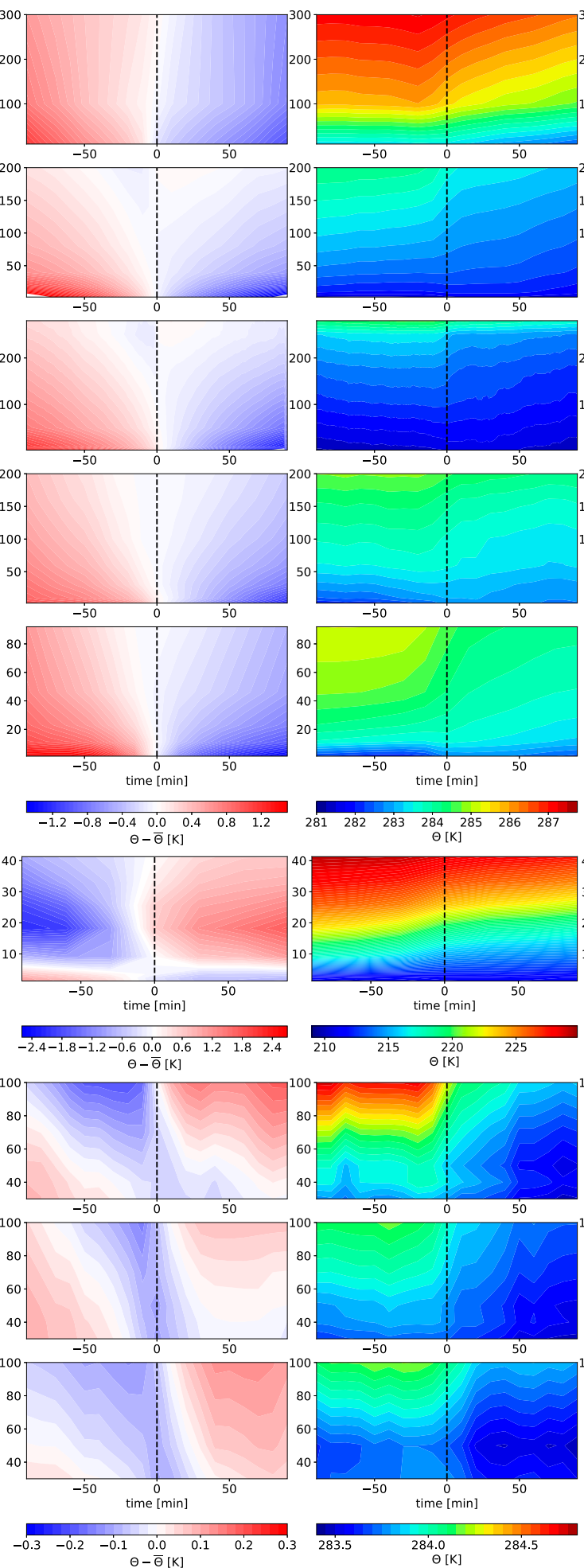

vSBL to wSBL transition
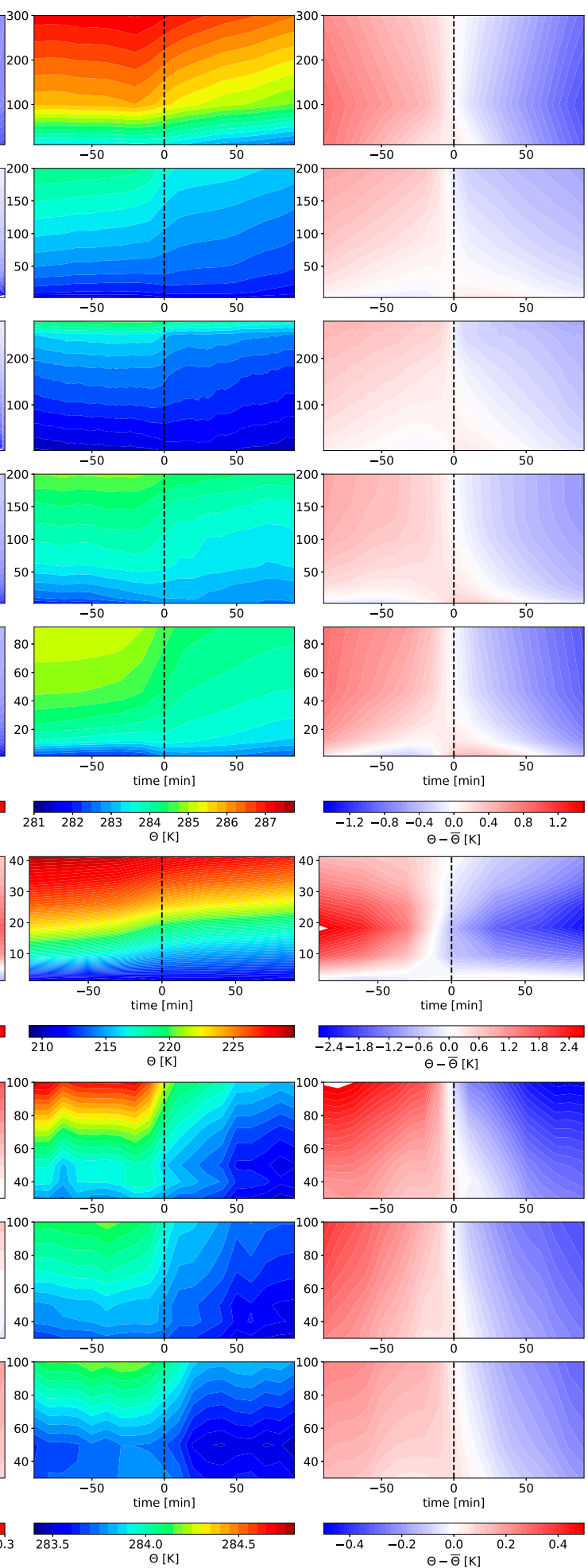

FIG. 2. As in Fig. 1, but for (first and third columns) potential temperature profiles and (second and fourth columns) their mean of deviations of the 180-min time mean during each transition. 
and the region extending from about $50 \mathrm{~m}$ to the surface. The strongest signal is near the surface in the moment of the transition.

With an increased inversion strength, vertical momentum transports are expected to be reduced causing the coupling of atmospheric layers to weaken. Conversely, vertical momentum transports should increase during turbulence recovery transitions and recouple atmospheric layers. Changes in the along- and acrosswind component during transitions provide information about changes in directional shear causing changes in the strength of coupling. Because the across-wind component is generally smaller than the along-wind component, behavior of the along-wind component during transitions broadly reflects that of the wind speed profiles (Fig. 3, first and third columns).

For these land-based stations we analyze composites of the absolute values of the across-wind component as the across-wind components take both positive and negative signs at stations located in mountain regions (not shown). The absolute across-wind component increases rapidly during wSBL-to-vSBL transitions, in particular below $100 \mathrm{~m}$ (Fig. 3, second column). The increase in the value of the across-wind component during the transition is largest at Boulder, Cabauw, and Hamburg. The relatively small magnitude of the change at Los Alamos is a consequence of the fact that the highest observational level is around $100 \mathrm{~m}$ (in contrast to $200-300 \mathrm{~m}$ at the other sites) and the across-wind components are calculated relative to this reference. Taking $100 \mathrm{~m}$ as the reference height at other sites results in across-wind magnitudes below $50 \mathrm{~m}$ similar to that observed at Los Alamos (not shown). Transitions from the vSBL to the wSBL are associated with a rapid decrease of the absolute across-wind component around the time of transition (Fig. 3, fourth column).

\section{2) Glacial-Based stations}

The extreme conditions at Dome $\mathrm{C}$ result in vertical scales of SBL transition structures being much smaller than at the land-based stations (Vignon et al. 2017b). Wind speed changes across transitions with magnitudes of about $2-3 \mathrm{~m} \mathrm{~s}^{-1}$ between 3 and $40 \mathrm{~m}$ at Dome $\mathrm{C}$ are similar to the values observed at land-based stations (Fig. 1, first and third columns). In contrast to the landbased stations there is no evidence of a subsequent development of a low-level jet at Dome $\mathrm{C}$ within the time range considered. The stratification shows a clear increase during wSBL-to-vSBL transitions, and a decrease during reverse transitions (Fig. 1, second and fourth columns). The mean stratification between 1 and $10 \mathrm{~m}$ increases from 1 to $6 \mathrm{~K}$ during times of turbulence collapse. Interestingly, the gradual increase in stratification following wSBL-to-vSBL transitions observed at landbased stations is not present at Dome C. Instead, a steady vSBL is rapidly established.

Evidence that radiative cooling at the surface is one mechanism leading to the formation of the inversion is provided by the fact that the 180-min anomaly of the potential temperatures in the lowest $10 \mathrm{~m}$ shows the same structure as the anomalies in the bottom few hundred meters at land-based sites (Fig. 2). Interestingly, the composite temperature above $10 \mathrm{~m}$ increases across wSBL-to-vSBL transitions. Such a development is a clear indicator of the advection of warm air. These results suggest that the composites contain both events in which transitions are driven by warm-air advection aloft (above $10 \mathrm{~m}$ ) or radiative cooling (below $10 \mathrm{~m}$ ). While temperature advection aloft may also influence regimes at the land-based stations [cf. evidence of such advection at Cabauw in Optis and Monahan (2017)] our results indicate that at these locations this process is less important than surface cooling.

An increase in the directional shear across times of wSBL-to-vSBL transitions is also evident in such a way that the upper and lower levels separated by the $10 \mathrm{~m}$ height increase in opposite directions (Fig. 3). Here, we do not consider the absolute value in order to depict the complex behavior of the across-wind component at this site. Relative to the land-based stations the across-wind component gradients at Dome $\mathrm{C}$ are much stronger, consistent with much stronger stratifications, which can sustain larger shears. In times of turbulence recovery, a decrease of the directional shear is evident below $20 \mathrm{~m}$ but not at higher altitudes. The signs of the across-wind component are consistent with the structure of an Ekman-like spiral in the Southern Hemisphere (Rysman et al. 2016).

\section{3) SEA-BASED STATiOnS}

At the FINO towers the atmospheric structures observed during transitions at land- and glacial-based stations are similar but the signals are smaller. Transitions from the wSBL to vSBL are evidently primarily driven by advection of warm air aloft, as these changes are associated with a temperature increase aloft rather than a cooling at the surface (Figs. 1, 2). The fact that sea-based stations experience wSBL-to-vSBL transitions due to advection of warm air is physically reasonable, as radiatively driven surface cooling over an ocean surface with high heat capacity is very weak. It is also possible that very shallow boundary layers cannot be detected at these sites because observations start at $30 \mathrm{~m}$.

Wind speed changes across times of transitions between the two SBL regimes are not as pronounced as over land- and glacial-based stations. However, wind speed decreases and increases can be associated with 

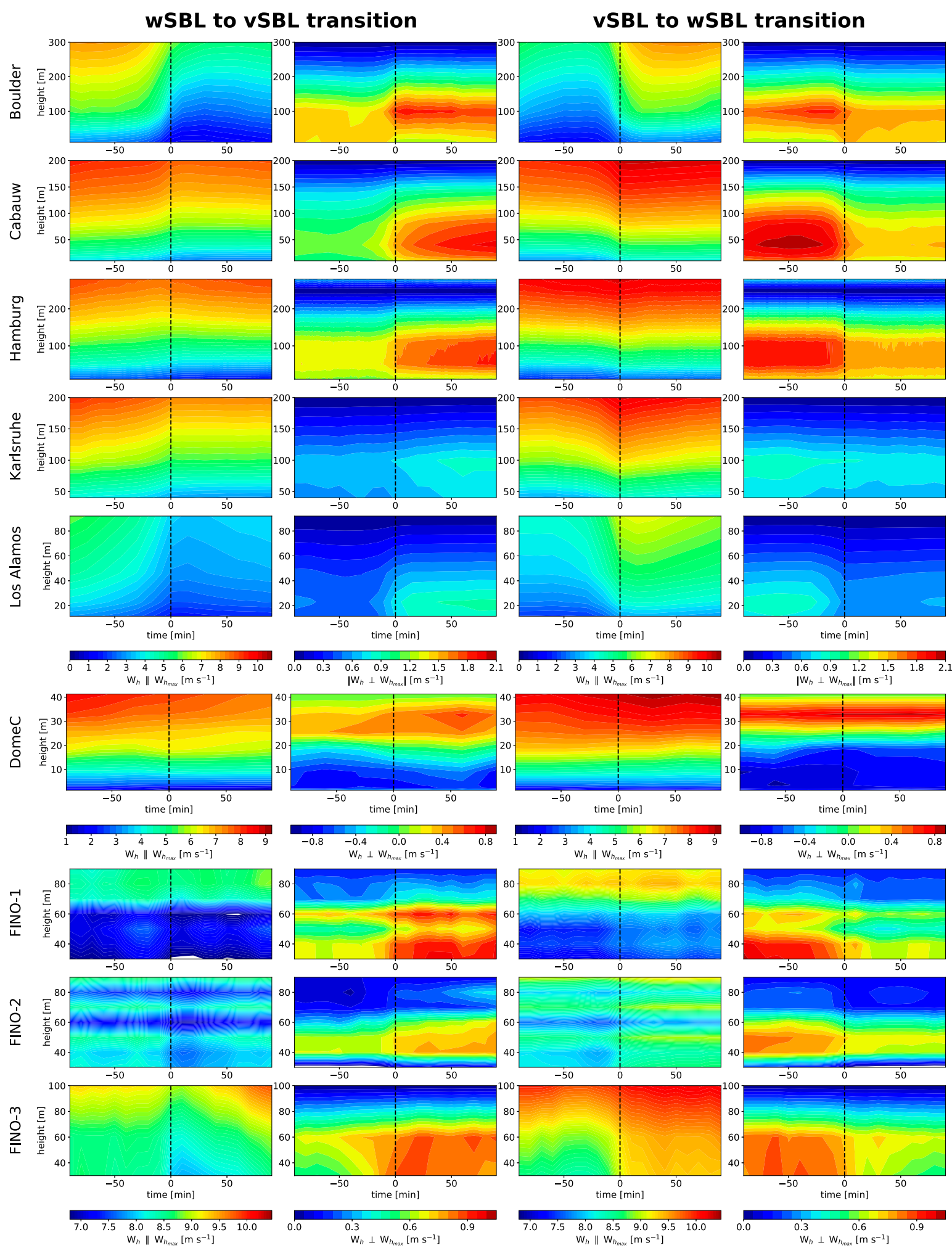

FIG. 3. As in Fig. 1, but for (first and third columns) along-wind and (second and fourth columns) across-wind component (absolute values at land-based stations) profiles. 
the, respectively, wSBL-to-vSBL and reverse transitions. Both SBL transitions show relatively fast changes in the flow and stratification and stay relatively steady after the moment of the transition in contrast to the slow buildup of stratification, which is observed over land.

The across-wind components at the sea-based stations exhibit the same structures as demonstrated for the land- and glacial-based stations, with relatively strong increases and decreases during SBL regime transitions due to changes in the vertical momentum transports (Fig. 3). The advection of warm air aloft at these locations leads to a pronounced vertical decoupling of atmospheric layers below about $60 \mathrm{~m}$ from those above.

\section{b. The structure of turbulence intensities across times of transitions}

Consistent with the evolution of Reynolds-averaged shear and stratification (which control TKE production and consumption), TKE values across times of transitions reflect the conceptual picture of transitions between strong and weak turbulence regimes. In constructing composites, we consider both means and medians because of the highly skewed TKE distribution. Turbulence data are available only at the land-based stations Cabauw, Hamburg, and Los Alamos.

The steadily increasing inversion strength preceding wSBL-to-vSBL transitions coincides with steadily decreasing TKE values (Fig. 4, first and second column). These transitions are marked by a clear turbulence collapse, such that mean TKE values decrease by one to two orders of magnitude. In contrast to Cabauw and Los Alamos, at Hamburg a shallow layer of weak turbulence persists in the vSBL. This feature appears to result from horizontal advection of TKE generated by flow over nearby rough urban elements. Conditioning the evolution of TKE profiles on wind directions from the east to southeast (for which the tower is upwind of the city) this residual TKE is almost absent (not shown). Strong contrasts between the SBL regimes are also evident in the variance of the vertical wind component $[\operatorname{var}(w)]$, a measure of the turbulence intensity, which is not influenced by nonturbulent two-dimensional motions. Composites of $\operatorname{var}(w)$ show that vertical motions are almost completely suppressed after wSBL-to-vSBL transitions. The collapse of $\operatorname{var}(w)$ is particularly evident in the median composite.

As a result of the suppression of vertical motion in strongly stably stratified conditions, we expect that the turbulence should be less isotropic in the vSBL than in the wSBL. We estimate this effect with the velocity aspect ratio, which we define as $3 \operatorname{var}(w) /[\operatorname{var}(u)+\operatorname{var}(v)+$ $\operatorname{var}(w)]$, where $u, v$, and $w$ are, respectively, zonal, meridional, and vertical wind components. This measure should take a value of 1 for isotropic turbulence. Particularly in the vSBL, subaveraging time-scale variations will include contributions from both turbulent and submeso motions. The relative contribution of these will depend on the averaging time scale. One difficulty in the direct comparison of isotropy characterized at the sites is therefore that the averaging times differ (from $1 \mathrm{~min}$ at Hamburg to $15 \mathrm{~min}$ at Los Alamos). While the quantitative behavior of the velocity aspect ratio will be affected by the different averaging times, we find similar qualitative structures across times of transitions. As expected, the velocity aspect ratio becomes smaller across the wSBL-to-vSBL transition (Fig. 4, first and second columns). In particular, at Los Alamos the variability aloft changes from almost perfectly isotropic to clearly anisotropic. While such strong changes in the velocity aspect ratio are not evident at Cabauw and Hamburg, the qualitative features of the changes agree.

As found with the Reynolds-averaged mean variables, the recovery of turbulence occurs on time scales of a few minutes. TKE recovers throughout the range of observed altitudes in less than $10 \mathrm{~min}$ for all of the tower sites considered (Fig. 4, third and fourth columns). TKE values after the transition increase by factors of 2 (Cabauw and Hamburg) and 4 (Los Alamos). Interestingly, at Cabauw and Hamburg the onset of turbulence appears to be located in the atmospheric layers between 50 and $100 \mathrm{~m}$. At Los Alamos the turbulence originates at altitudes above the observational levels. These results are broadly consistent with the picture of top-down turbulent bursts breaking down the inversion (e.g., Acevedo et al. 2006; Basu et al. 2006), possibly due to intermittent turbulence events such as breaking gravity waves. The fact that the medians of $\operatorname{var}(w)$ before a turbulence recovery event are much weaker than afterward indicates that there are many cases in which the onset of turbulence is abrupt.

The average TKE before turbulence recovery is larger than that immediately after a turbulence collapse. At Hamburg, vertical fluctuations show larger values before a recovery than after collapse. One possible explanation of slightly larger TKE values before a recovery event than after a collapse event is the accumulation of TKE by relatively small intermittent turbulence events, which weaken the stratification to the point of initiating a transition to the wSBL.

Other turbulent state variables such as the magnitudes of the turbulent stresses show similar results (not shown). While turbulent heat fluxes toward the surface decrease during times of turbulence collapse and increase during recovery, they do not show such large changes as the momentum turbulent fluxes. This result is consistent with the fact that same heat fluxes can result 


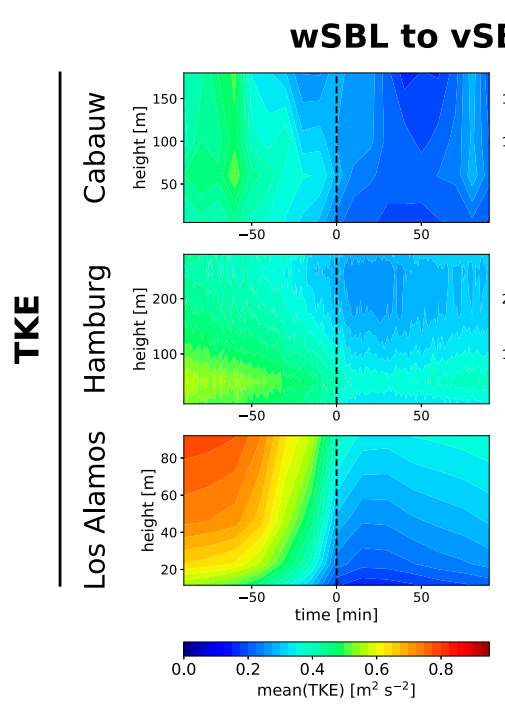

\section{BL transition}
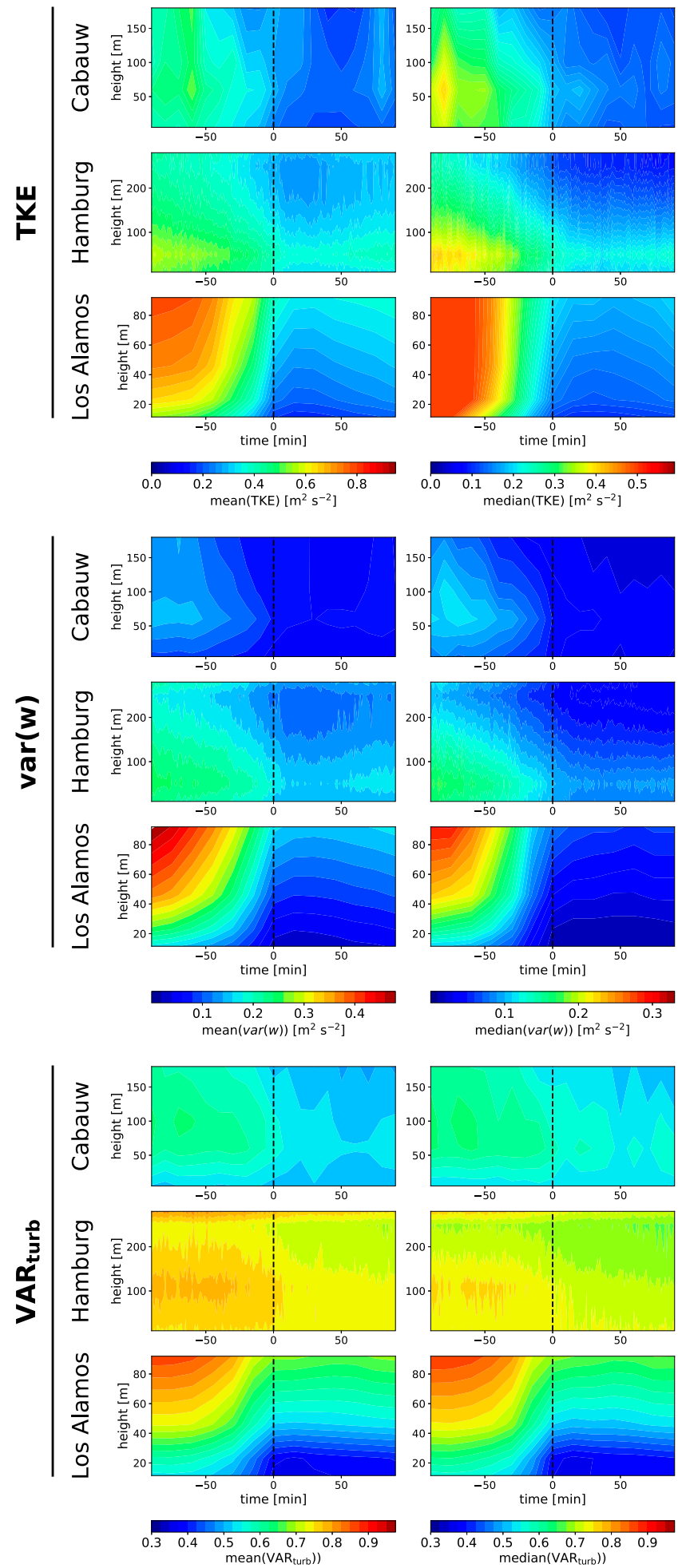
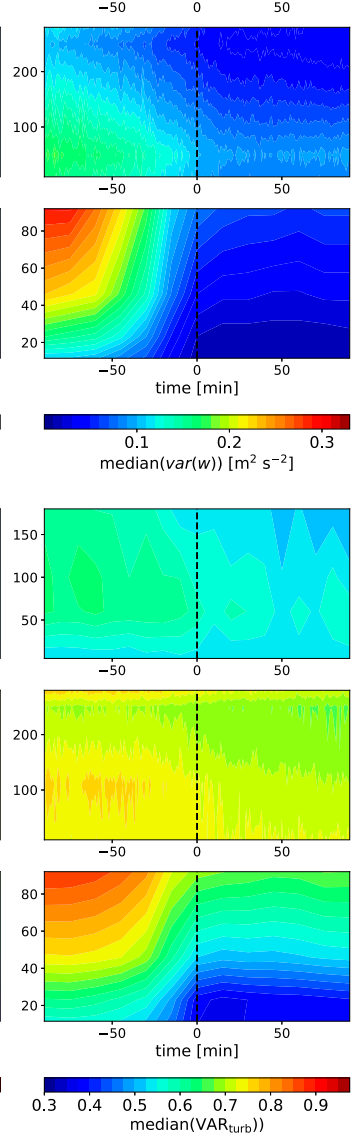

vSBL to wSBL transition
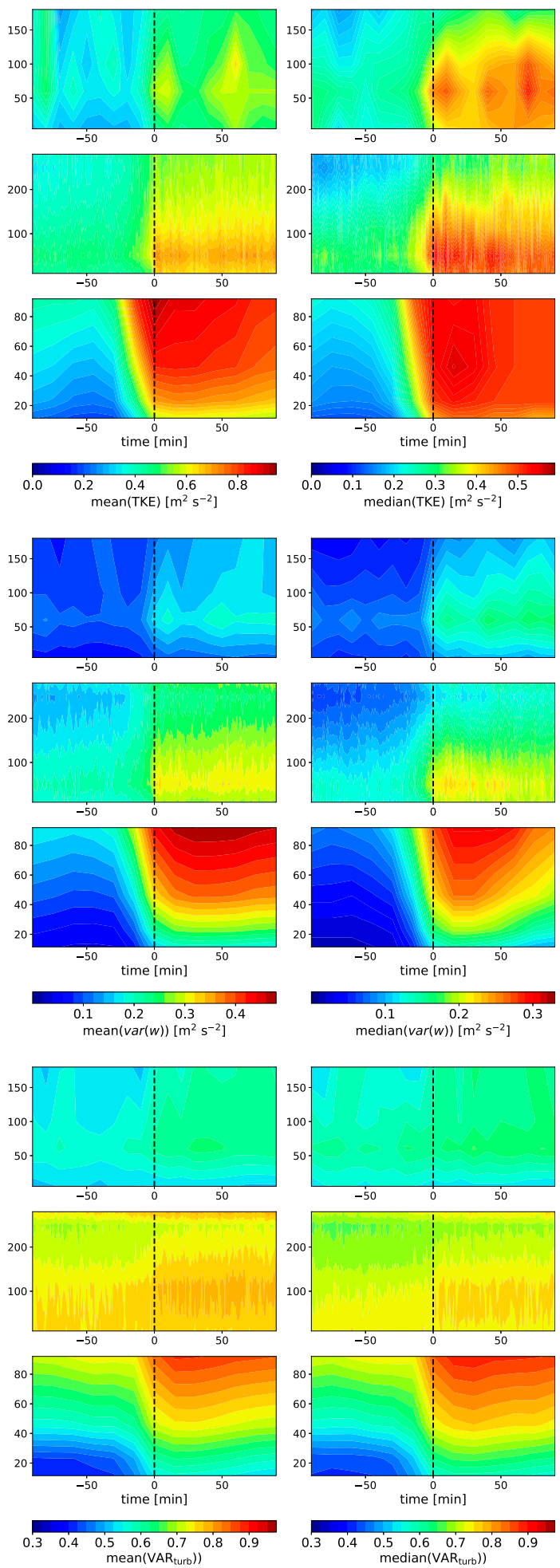

FIG. 4. Time evolution of the (first and third columns) composite means and (second and fourth columns) composite medians of (top) TKE profiles, (middle) the variance in the vertical wind component $w[\operatorname{var}(w)]$, and (bottom) the velocity aspect $\operatorname{ratio}\{3 \operatorname{var}(w) /[\operatorname{var}(u)+$ $\operatorname{var}(v)+\operatorname{var}(w)]\}$ of turbulence profiles $\left(\mathrm{VAR}_{\text {turb }}\right)$ at the different tower sites where turbulence data is available in times of (first and second columns) turbulence collapse (wSBL-to-vSBL transition) and (third and fourth columns) turbulence recovery (vSBL-to-wSBL transition) as determined by the HMM analyses. The composites show the $90 \mathrm{~min}$ before and after the transitions at time $t=0$ (dashed reference line). 
from strong stratification with weak turbulence or weak stratification with relatively strong turbulence (e.g., van de Wiel et al. 2012a,b, 2017).

\section{c. The boundary layer structures in very persistent wSBL and $v S B L$ nights}

We now consider the composite state-variable profiles during very persistent nights. In this discussion we do not consider the glacial-based station because the duration of the polar nights is much longer than at the other midlatitude stations considered. A direct comparisons of Reynolds-averaged mean profiles during very persistent nights at stations with well-defined nights to this station is not particularly meaningful.

While distributions of Reynolds-averaged mean meteorological state variables show substantial overlaps for both regimes if the whole time series are considered (AM19a), distributions of those variables conditioned on the occurrence of very persistent nights show much clearer differences in wind and stratification profiles at land-based stations (Fig. 5; note again that the vertical axes differ between tower sites and that stratification is calculated as the potential temperature difference between each height and the measurement nearest the surface). These differences are similar to the profiles within regimes outside of the 180-min time window around regime transitions considered above. The relatively clear separation of stratification profiles relative to wind speed profiles is consistent with the fact that inversion strength is expected to change rapidly over a relatively narrow band of wind speeds (van de Wiel et al. 2017).

As expected for land-based stations, very persistent wSBL nights are characterized by strong winds at all altitudes, while wind speeds are substantially smaller in very persistent vSBL nights. Accordingly, near-surface shears are stronger in very persistent wSBL than in very persistent vSBL nights. At Boulder, Cabauw, and Los Alamos the interquartile ranges of wind profiles are well separated. At Hamburg and Karlsruhe the separation of the wind profile distributions is weaker, consistent with the fact that wind speed changes across regime transitions are also weaker at those sites. The weaker separation of wind profiles at Hamburg and Karlsruhe may be related to the fact that both tower sites are close to urban regions, which can decelerate the wind speeds in the wSBL substantially due to their larger surface roughness. Additionally, Karlsruhe is also located in the Rhine valley and therefore in the wind shadow of the surrounding hills. While Los Alamos is also located in a valley, the different surface properties (grassland at Karlsruhe versus sandy dry surface at Los Alamos) can affect the strength of the inversion induced by radiative cooling and therefore the turbulence and the nearsurface shear, which may be responsible for clearer separations of the wind profiles.

The stratification profiles are well separated across all land-based stations, showing how strong the signal of very persistent nights is in the potential temperature field. The very persistent wSBL nights have an almost neutral temperature profile whereas in the very persistent vSBL the potential temperature gradients are large (particularly near the surface). Across the towers, the potential temperature difference between the lowest measured altitude and about $100 \mathrm{~m}$ is between 2 and $6 \mathrm{~K}$. Los Alamos shows a particularly large near-surface stratification, which is matched in intensity only at Karlsruhe. Quantitative differences in our measure of stratification between sites are likely partially due to differences in the height of the lowest observational level, as vSBL near-surface temperature gradients are particularly strong [cf. differences in stratification at Cabauw illustrated in Fig. 1 of van de Wiel et al. (2017) and Fig. 5 in this study].

At all sea-based FINO towers, the clear separation between very persistent nights is only evident in the stratification profiles (Fig. 6). Relatively small differences in wind speed profiles are evident in the overlap of the interquartile ranges. These results are consistent with the fact that across regime transitions changes in flow at sea-based stations are less pronounced than changes in stratification (section 3a). At FINO-1 and FINO-3 the mean profiles have larger wind speeds at all altitudes in very persistent wSBL nights than in very persistent vSBL nights. Such a systematic difference is not present at FINO-2 where mean wind profiles are very similar in both types of persistent nights. Interestingly, FINO-2 shows stronger shears above the lowest observational level in the very persistent vSBL than in the very persistent wSBL nights suggesting a much stronger decoupling of atmospheric layers in very persistent vSBL nights than at the other sea-based sites although the stratification profiles are not considerably different. Consistent with the other sites the near-surface shears at FINO-2 are also larger in the very persistent wSBL in comparison to very persistent vSBL nights.

As the underlying water at these stations has a high heat capacity and the surface shows smaller variations in temperature than surfaces at the land-based stations, the buildup of strong stratification by surface radiative cooling is reduced. The evolution of composite potential temperature profiles from just before the sunset to $8 \mathrm{~h}$ afterward shows that the strong stratification in the vSBL is primarily due the presence of warm air aloft rather than surface cooling (Fig. 7, right column). A natural interpretation of very persistent vSBL nights at 

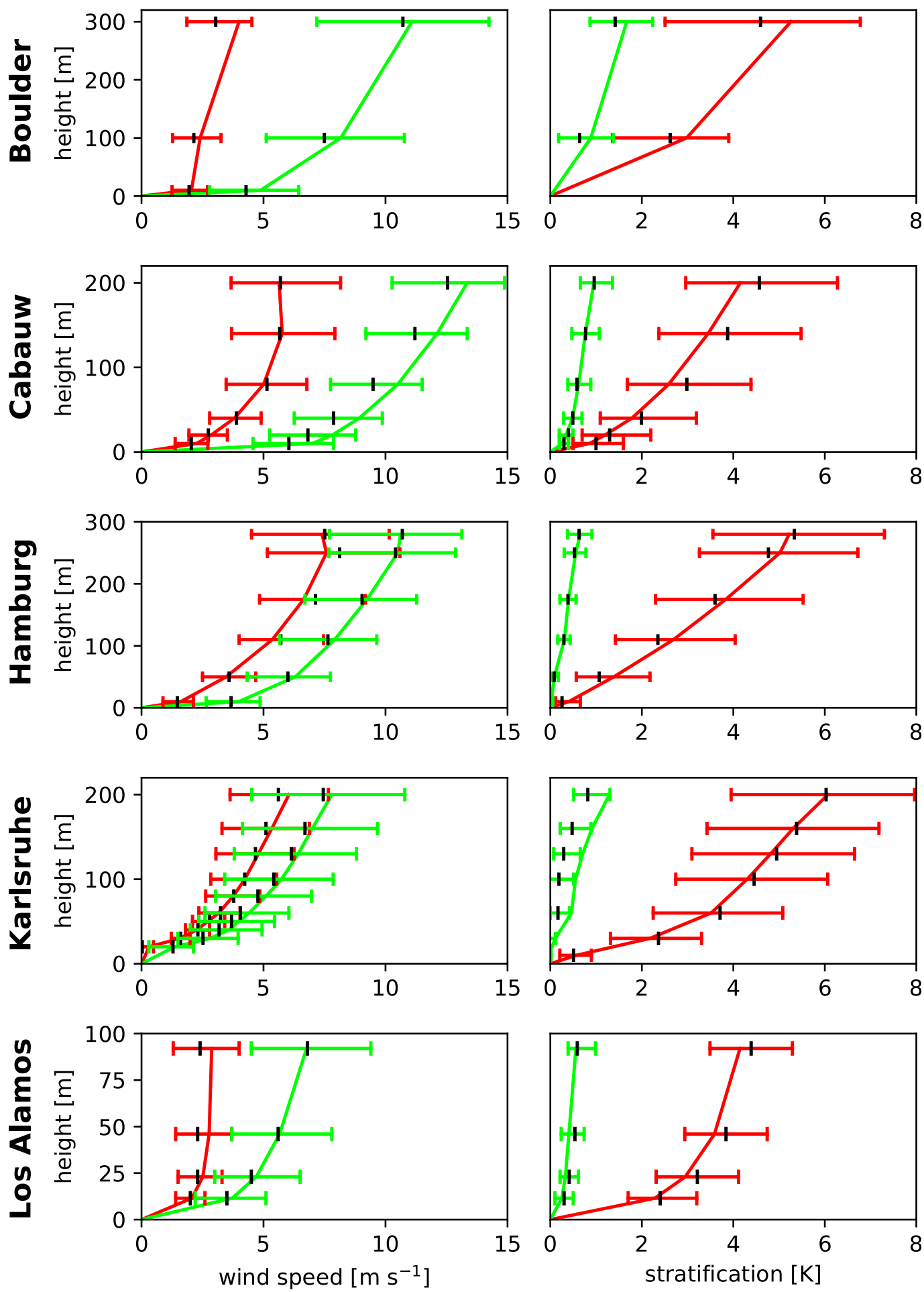

FIG. 5. (left) Wind and (right) stratification mean profiles of nights remaining exclusively in the wSBL (green) and vSBL (red) as classified by the reference HMMs for the land-based stations. Lines denote the mean, while horizontal bars indicate the 25 th-75th quartiles. The median is marked in black. 

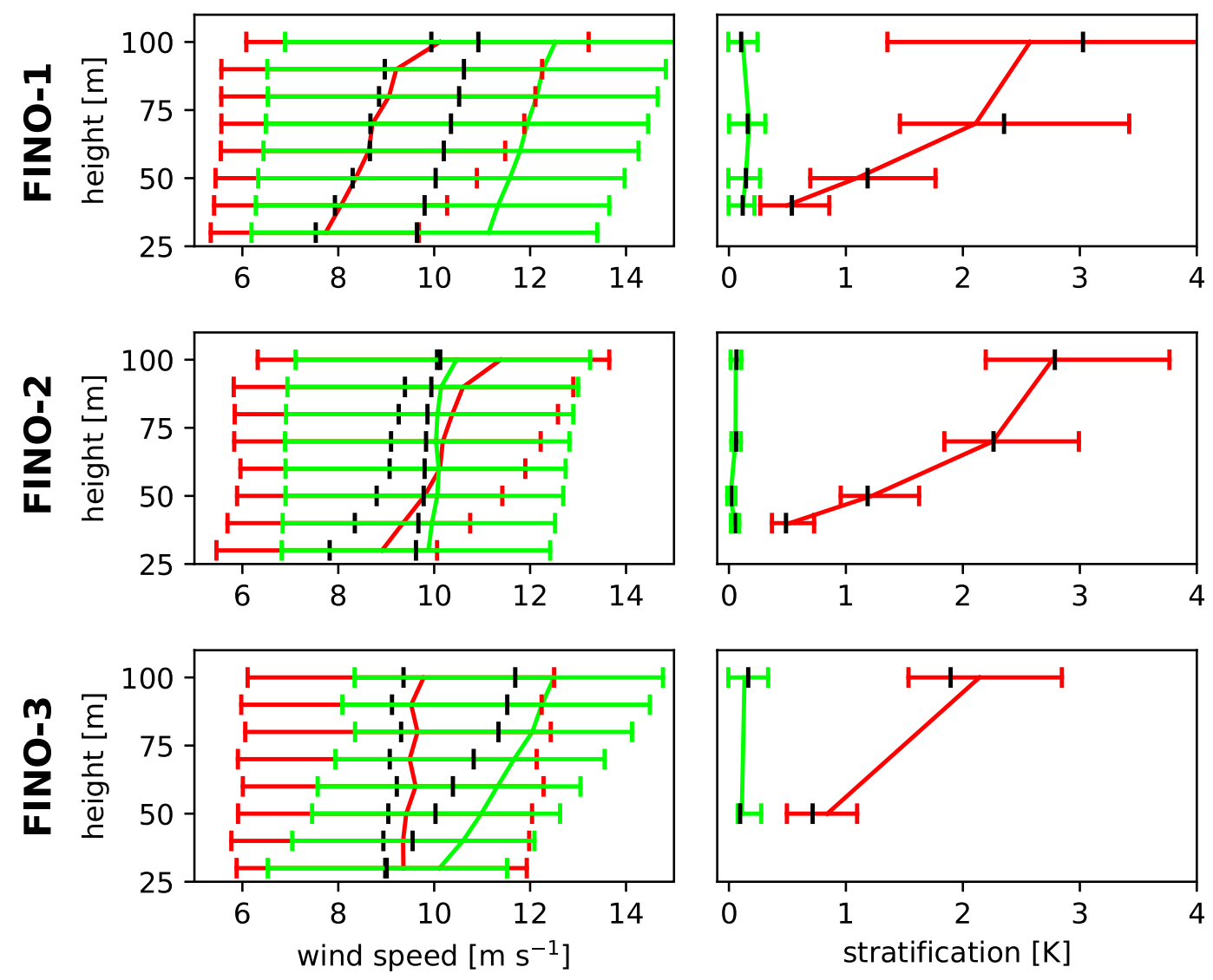

FIG. 6. As in Fig. 5, but for the sea-based stations.

sea-based stations is that these arise due to the horizontal advection of warm air aloft, consistent with the findings at FINO-2 in Dörenkämper et al. (2015) and with the fact that transitions have a dominant advection signal at these sites (cf. section $3 a$ ). The very persistent wSBL nights, on the other hand, show a slow cooling of the air with a near-neutral stratification demonstrating how well mixed (due to sustained turbulence) the boundary layer at observed atmospheric layers is.

We expect that reductions of turbulent momentum fluxes in the vSBL decouple the atmospheric layers resulting in larger vertical directional shears as demonstrated above in the increase in the across-wind components in section 3a. Accordingly, a clear separation of the across-wind component mean profiles between regimes exists across all tower sites between the very persistent vSBL and very persistent wSBL nights (not shown). The mean differences in the across-wind component between the very persistent wSBL and vSBL (about $1-2 \mathrm{~m} \mathrm{~s}^{-1}$ ) are almost exactly the mean values as found before and after regime transitions showing that a sort of maximum in the directional shear exists independent of how long the vSBL is occupied. Although at the sea-based stations the along-wind components do not differ in the two very persistent regimes the acrosswind components show a clear decoupling (not shown).

As with the stratification, TKE is separated well between the very persistent SBL nights (Fig. 8). The same is true of for $\operatorname{var}(w)$. Across all locations with variance measurements of the Reynolds-averaged data the median in $\operatorname{var}(w)$ is very close to zero for very persistent vSBL nights showing how effectively vertical fluctuations are suppressed. Interestingly, values of TKE and $\operatorname{var}(w)$ systematically increase with height at Los Alamos in both types of very persistent nights. In the case of very persistent wSBL nights during which largest TKE values are expected where shears are strongest (near the surface; Fig. 5) this result provides further evidence of a lack of horizontal homogeneity of the turbulence at this location. Naturally, the very persistent vSBL nights show at all stations evidence of an increase of TKE with height due to the possibility of the buildup of a low-level jet (as demonstrated during wSBL-to-vSBL transitions, Fig. 1), which produce TKE and top-down turbulence bursts (e.g., Mahrt 2014).

Across the tower stations for which turbulence intensities are provided the variability of TKE and $\operatorname{var}(w)$ 

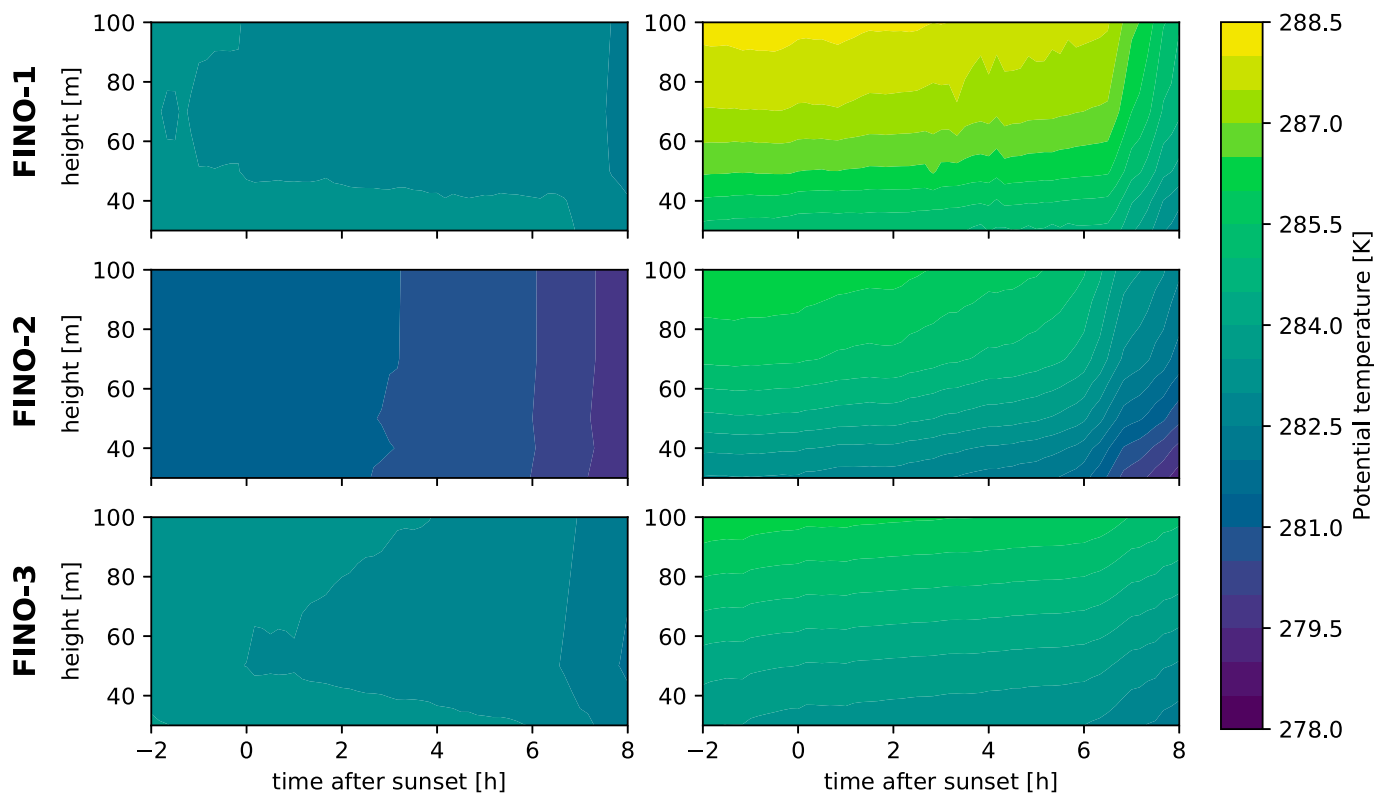

FIG. 7. Evolution of the mean potential temperature profiles of nights remaining exclusively in the (left) wSBL and (right) vSBL as classified by the reference HMMs for the sea-based stations.

within the vSBL nights is generally small, and the fact that the mean values of these quantities generally exceed the 75th percentiles indicate highly skewed distributions. Under very stable conditions bursts of turbulence are observed (e.g., van de Wiel et al. 2003; Mahrt 2014). These intermittent turbulence events are evidently not strong enough to break down the stratification and do not result in a transition to the wSBL, as by construction only persistent vSBL nights are considered. The distributions of TKE and $\operatorname{var}(w)$ are clearly skewed in the very persistent wSBL nights, but much less so than in the very persistent vSBL nights.

The friction velocity there expressed as $U_{*}(z)=$ $\left.\left[{\overline{u^{\prime} w^{\prime}}}^{2}(z)+{\overline{v^{\prime} w^{\prime}}}^{2}(z)\right]^{1 / 4}\right\}$ is also clearly separated between large values in the very persistent wSBL and small values in the very persistent vSBL (Fig. 9, left column). Again, the distributions are positively skewed with larger skewness in the very persistent vSBL nights. Differences in turbulent kinematic heat fluxes $\overline{w^{\prime} T^{\prime}}(z)$ between the very persistent nights are small (in Cabauw) or absent (in Hamburg), consistent with the maximum sustainable downward heat flux (MSHF) perspective (Fig. 9, right panels). If the top of the boundary layer is defined as the height where $\overline{w^{\prime} T^{\prime}}$ approaches zero, Cabauw exhibits very shallow boundary layers (below $100 \mathrm{~m}$ ) in very persistent vSBL nights. In contrast during regime transitions the top of the boundary layer does not approach such shallow boundary layers (not shown). The stronger wSBL turbulent heat fluxes at Cabauw might be related to the fact that the stratification is slightly stronger than at Hamburg (Fig. 5) while the $\operatorname{var}(w)$ values (indicative of the vertical turbulent transports) are very similar at both sites (Fig. 8). Interestingly, at Hamburg considerable amounts of time in very persistent wSBL nights are associated with positive (upward) heat fluxes though all stratification measurements are positive. The reason for these countergradient heat fluxes is unclear.

\section{$d$. The evolution of the very persistent $w S B L$ and $v S B L$ over the course of the night}

The time evolution of the stratification and nearsurface shear (as represented by the near-surface wind speed) is now investigated in order to understand the temporal behavior of the competing mechanisms of TKE consumption and production in very persistent nights (Fig. 10). We chose to measure the stratification using the observational levels closest to $100 \mathrm{~m}$ and the surface as these heights allow for the best possible direct comparison between all tower sites. We consider here only the first eight night hours, the length of the shortest nights in a year at around $45^{\circ} \mathrm{N}$. Analyses of the individual seasons analyses produce very similar results (not shown).

Relatively strong wind speeds are found in the entire very persistent wSBL night (Fig. 10), consistent with sustained relatively large shear generation of turbulence. Across all land-based stations the stratification develops in broadly similar ways. Before sunset, stratification increases slightly from near-neutral to weakly 

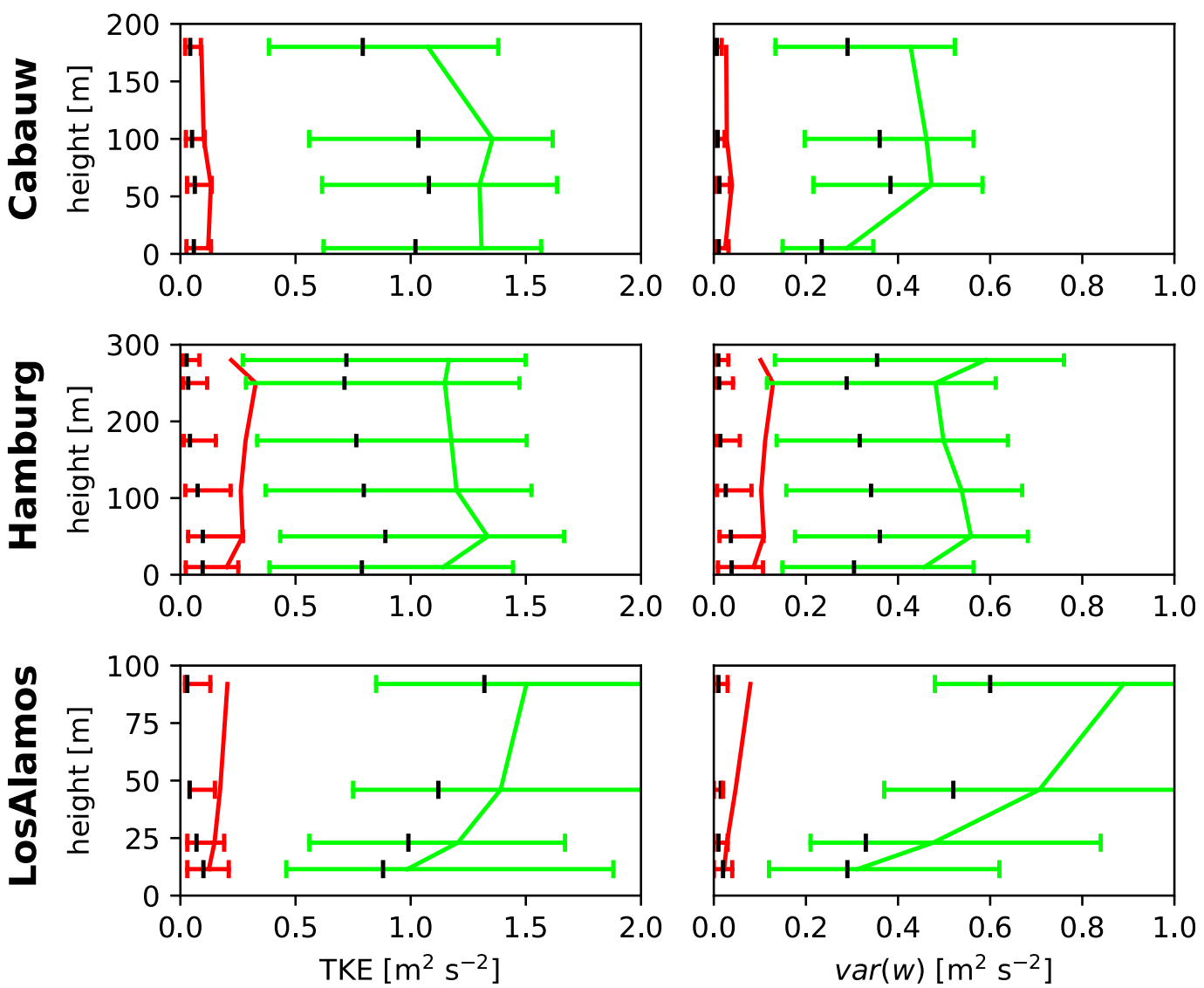

FIG. 8. As in Fig. 5, but for profiles of (left) TKE and (right) the variance of the vertical wind component [var( $(w)]$. These data are only available for (top) Cabauw, (middle) Hamburg, and (bottom) Los Alamos.

stable conditions. The pdfs of tendencies of the stratification before and after sunset reveal that the very persistent wSBL is completely established at the time of sunset (not shown).

The strongest stratification values in very persistent wSBL nights occur in Boulder and Los Alamos, the stations where strong radiative cooling can occur due to climatological low cloud coverage. The midlatitude European sites show all very similar mean stratification values, which are systematically smaller than at the American sites. The positive skewness of stratification at Karlsruhe evident in the fact that the mean generally exceeds the 75th percentile is not observed at other stations, and may result from measurement inaccuracy (the median stratification value is close to zero). While the very persistent near-surface wind speeds are similar across most sites, relatively low wind speeds are observed at Karlsruhe. The reasons for this different behavior at Karlsruhe are not clear.

Very persistent vSBL nights already show stratification values of $1-2 \mathrm{~K}$ in the bottom $100 \mathrm{~m} 2 \mathrm{~h}$ before sunset and rapidly increase to about 4-5 K (Fig. 10, left column). With the exception of Boulder where the stratification continues to gradually increase, these strong stratifications are completely developed within $1-2 \mathrm{~h}$ after sunset. A possible reason for this different behavior at Boulder is the greater height of the nearsurface temperature measurement $(10 \mathrm{~m}$ as opposed to $2 \mathrm{~m}$ at most other stations), such that the temperature at this altitude exhibits a delayed response to surface cooling. In contrast to other sites at which the stratification is relatively constant or increasing throughout the night, at Karlsruhe the stratification takes a maximum shortly after sunset and decreases again. The developed vSBL corresponds to low wind speeds of about $2 \mathrm{~m} \mathrm{~s}^{-1}$ at all tower stations except Karlsruhe (Fig. 10, right column), where about $50 \%$ of the measurements show a near-zero wind speed near the surface. Interestingly, at Boulder and Los Alamos wind speeds decrease after an initial increase near sunset. While the very persistent wSBL is completely established at sunset, pdfs of the very persistent vSBL stratification tendencies show distributions centered around positive values to about $1-2 \mathrm{~h}$ after sunset, 

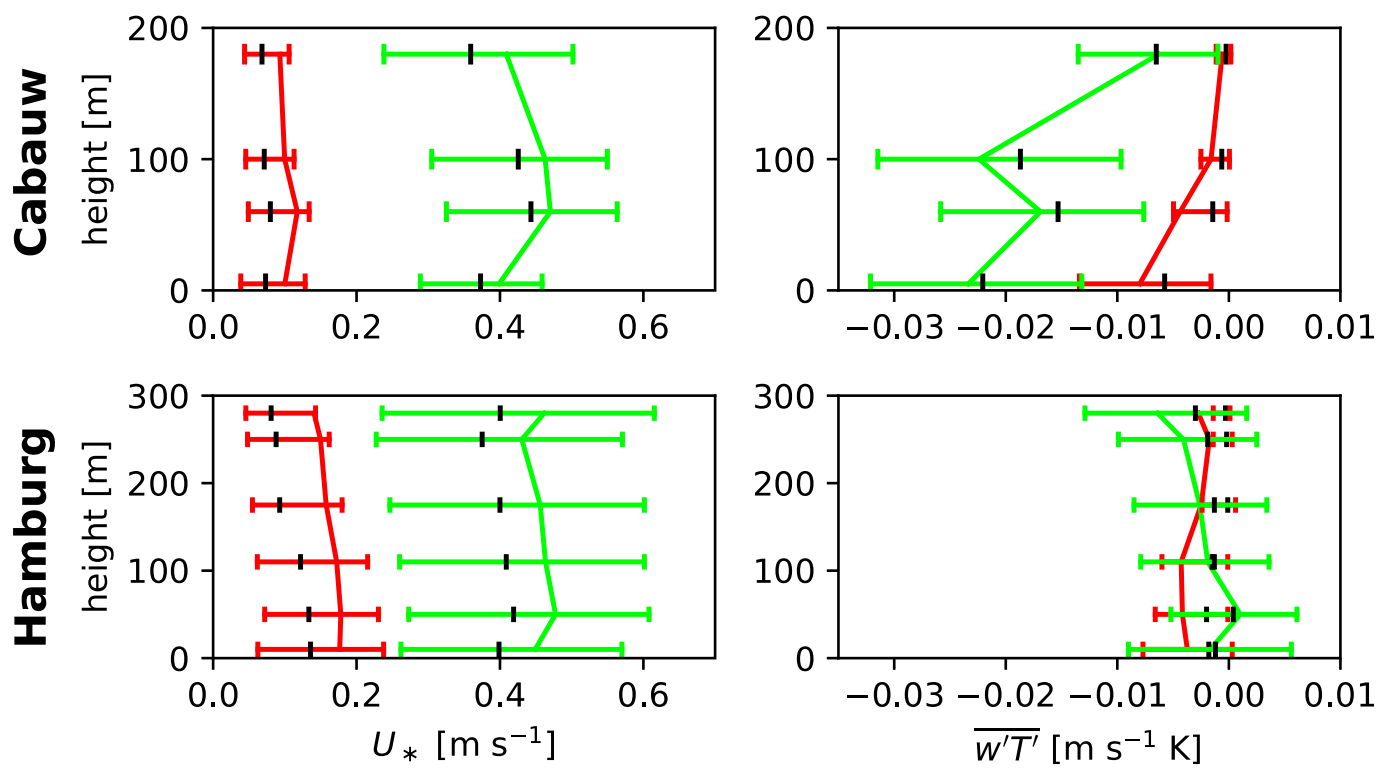

FIG. 9. As Fig. 8, but for the (left) friction velocity $U_{*}$ and (right) turbulent kinematic heat flux $\overline{w^{\prime} T^{\prime}}$. These data are only available for (top) Cabauw and (bottom) Hamburg.

after which the tendencies are distributed narrowly around zero (not shown).

During very persistent wSBL nights the variability in stratification is considerably lower than the variability for very persistent vSBL nights. The vice versa is true for the near-surface wind speeds in the two regimes (Fig. 10). These differences are broadly consistent with the shear capacity framework put forward in van Hooijdonk et al. (2015). Previous studies have shown that scatterplots of stratification and near-surface wind speed show an "L" shape, such that small values of nearsurface wind speed (corresponding to the vSBL) are associated with a large range of stratifications and a broad large range of relatively large wind speeds correspond to weak stratification (Monahan et al. 2015; van de Wiel et al. 2017; AM19a).

For sea-based stations the role of warm-air advection was discussed above (Fig. 7). The evolution of the wind speeds over the course of the night has a considerable variability and no clear separation between very persistent wSBL and vSBL nights is evident (not shown).

\section{Conclusions}

Regime sequences obtained from a hidden Markov model (HMM) allow for systematic characterization of the climatological mean behavior of meteorological state variables during regime transitions in the nocturnal stably stratified boundary layer (SBL) and in nights without transitions ("very persistent nights") at nine different tower sites. In this study we relied on the simplest classification scheme of the SBL separating weakly stable (wSBL) from very stable (vSBL) conditions.

Composites of the Reynolds-averaged mean and variance (turbulence) state variables, considering the $90 \mathrm{~min}$ before and after each transition, show generic structures across land-based tower sites. Across these stations, radiative cooling at the surface causes a continual decrease in the temperatures near the surface building up the inversion strength, which results in the wSBL-to-vSBL transition. We find that in more arid areas the new steady vSBL state is reached faster than in humid surroundings. The enhanced inversion strength decreases resulting in vertical decoupling of the dynamics, most evident in the increase of the wind components perpendicular to the direction of the flow at the highest observational level. Turbulent kinetic energy (TKE) values show a strong decrease to complete collapse in wSBL-to-vSBL transitions and while the velocity aspect ratio of turbulence decreases. Vertical fluctuations are almost completely suppressed after a wSBL-to-vSBL transition.

Across land-based stations. the recovery of turbulence happens on time scales of a few minutes. The turbulence recovers throughout all observational levels starting between 50 and $100 \mathrm{~m}$. In times of these transitions, the vertical velocity variance becomes larger and wind fluctuations become more isotropic. The recovery of turbulence leads to the weakening of the inversion and the coupling of the atmospheric levels. The across-wind component decreases abruptly and the along-wind component accelerates in all atmospheric levels. 

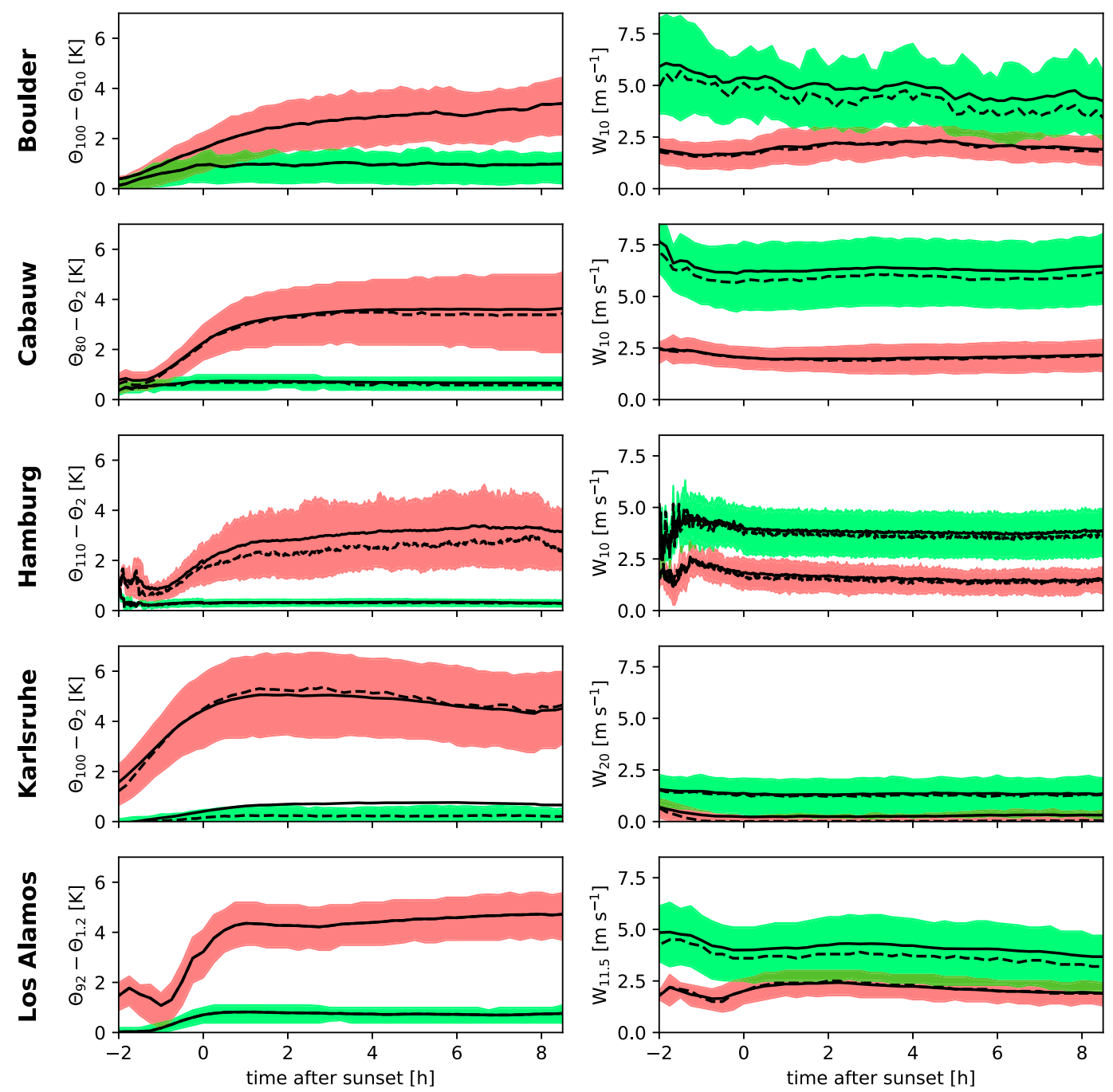

FIG. 10. Evolution of the (left) stratification and (right) near-surface wind speed in nights remaining exclusively in the wSBL (green) and in the vSBL (red) as classified by the reference HMMs for the land-based stations. The means are depicted by the black solid lines, the medians by the black dashed lines, and the $25^{\text {th }}$ and 75 th percentiles by the green and red contours, respectively.

Similar results are found at the glacial-based station of Dome $\mathrm{C}$, although there is evidence here to indicate that advection of warm air aloft is also an important mechanism leading to turbulence collapse. A more detailed analysis of differences between transitions caused by advection of warm air aloft or radiative cooling at the surface is an interesting direction for future research.

At sea-based sites wSBL-to-vSBL transitions are clearly related to the advection of warm air aloft. Therefore, during transitions changes are more pronounced in the stratification than in the flow. Consistent with the fact that stratifications are generally weaker than over land and ice-snow, decoupling of the atmospheric layers in the vSBL is weaker. Nevertheless, winds decrease and increase with respect to wSBL-to-vSBL and reverse transitions, and the across-wind component shows clear evidence of vertical decoupling and coupling.

In contrast to the distributions of state variables at times of SBL regime transitions (AM19a), stratification and wind profiles show a clear separation between the two regimes in very persistent nights across the landbased stations. The wSBL is governed by consistently strong and almost unchanging wind conditions during the entire night sustaining strong TKE production and maintaining the weak stratification. The very persistent vSBL nights, on the other hand, are governed by consistently weak wind conditions during the entire duration of the night. Due to the initial surface radiative cooling around sunset the temperature profiles adjust up to about $2 \mathrm{~h}$ after sunset and generally stay steady 
afterward. Measurements of turbulent heat fluxes further suggest that very persistent vSBL nights are characterized by shallow (below $100 \mathrm{~m}$ ) boundary layers. At the seabased stations the wind profiles are not separated between very persistent vSBL and wSBL nights. At these locations, the very persistent $\mathrm{vSBL}$ is induced by the advection of warm air aloft rather than by surface cooling.

Mean profiles of meteorological state variables in very persistent nights are very similar to those of the wSBL and vSBL outside of the time immediately before and after transitions. It follows that a considerable overlap of state-variable distributions between nights with and without transitions exist even though the two classes of very persistent nights are well separated. All in all, there is no clear indicator in Reynolds-averaged mean variables that leads to the buildup of very persistent nights or nights with transitions. As has been demonstrated in AM19b external drivers such as the low-level cloud coverage or geostrophic wind are also not a clear predictor of the occurrence of very persistent nights or nights with transitions. The absence of clear separations between internal or external variables in nights with and without transitions provides further evidence of the need to account for regime occupation and transitions probabilistically rather than deterministically in weather and climate models.

Acknowledgments. We thank a number of individuals and institutes for their willingness to share their tower data, which were indispensable in carrying out this extensive comparison of SBL structures at different location sites. Our acknowledgements are presented in the order that the tower stations were presented in the paper, but we are equally thankful to all. The NOAA Earth System Research Laboratory's (ESRL) Physical Sciences Division (PSD) operates the Boulder Atmospheric Observatory (BAO) tower and makes the data publicly available (information how to obtain the data is given on https://www.esrl.noaa.gov/psd/technology/bao/site/). The Royal Netherlands Meteorological Institute (KNMI) is thanked for providing tower data from the Cabauw Experimental Site for Atmospheric Research (CESAR) (which can be downloaded at http://www.cesardatabase.nl). Fred Bosveld from the KNMI is acknowledged in particular for providing one year of turbulence data from CESAR. Felix Ament and Ingo Lange provided an extensive amount of Reynoldsaveraged and turbulence data from the Wettermast Hamburg of the Meteorological Institute of the University of Hamburg. Martin Kohler and the Institute for Meteorology and Climate Research of the Karlsruhe Institute of Technology (KIT) provided observations from the turbulence and meteorological mast in Karlsruhe. The French and Italian polar institutes (IPEV and PANRA, respectively) that operate the Dome $\mathrm{C}$ observatory in Antarctica are acknowledged for providing data through IPEV (program CALVA 1013), INSU/LEFE (GABLS4 and DEPHY2), and OSUG (GLACIOCLIM). The data are available on the CALVA website (http:// lgge.osug.fr/ genthon/calva/home.shtml). The team of the Los Alamos National Laboratory (LANL) are thanked making data from the Environmental Monitoring Plan (EMP) freely available (which can be downloaded from http://environweb.lanl.gov/weathermachine/ data_request_green_weather.asp). The Bundesamt für Seeschifffahrt und Hydrographie (BSH), the Bundesministeriums für Wirtschaft und Energie (BMWi), the Projektträger Jülich (PTJ), and Olaf Outzen are thanked for granting access to the data from the offshore research platforms FINO-1, FINO-2, and FINO-3 in Germany.

Carsten Abraham and Adam H. Monahan are supported by the Natural Sciences and Engineering Research Council Canada (NSERC). The authors thank Yanping He, Amber Holdsworth, Ivo G. S. van Hooijdonk, Norman McFarlane, Ron McTaggartCowan, and Bas J. H. van de Wiel for useful discussions as well as three anonymous reviewers whose suggestions substantially improved this manuscript.

\section{REFERENCES}

Abraham, C., and A. H. Monahan, 2019a: Climatological features of the weakly and very stably stratified nocturnal boundary layers. Part I: State variables containing information about regime occupation. J. Atmos. Sci., 76, 3455-3484, https:// doi.org/10.1175/JAS-D-18-0261.1.

$\longrightarrow$, and $-2019 \mathrm{~b}$ : Climatological features of the weakly and very stably stratified nocturnal boundary layers. Part II: Regime occupation and transition statistics and the influence of external drivers. J. Atmos. Sci. 76, 3485-3504, https://doi.org/10.1175/JAS-D-19-0078.1.

_ A. M. Holdsworth, and A. H. Monahan, 2019: A prototype stochastic parameterization of regime behaviour in the stably stratified atmospheric boundary layer. Nonlinear Processes Geophys., in press.

Acevedo, O. C., and D. R. Fitzjarrald, 2003: In the core of the night-effects of intermittent mixing on a horizontally heterogeneous surface. Bound.-Layer Meteor., 106, 1-33, https:// doi.org/10.1023/A:1020824109575.

— , O. L. L. Moraes, G. A. Degrazia, and L. E. Medeiros, 2006: Intermittency and the exchange of scalars in the nocturnal surface layer. Bound.-Layer Meteor., 119, 41-55, https:// doi.org/10.1007/s10546-005-9019-3.

_ L. Mahrt, F. S. Puhales, F. D. Costa, L. E. Medeiros, and G. A. Degrazia, 2016: Contrasting structures between the decoupled and coupled states of the stable boundary layer. Quart. J. Roy. Meteor. Soc., 142, 693-702, https://doi.org/10.1002/qj.2693.

— , R. Maroneze, F. D. Costa, F. S. Puhales, L. G. Nogueira Martins, P. E. Soares de Oliveira, and L. Mortarini, 2019: The nocturnal boundary layer transition from weakly to very 
stable. Part 1: Observations. Quart. J. Roy. Meteor. Soc., https://doi.org/10.1002/QJ.3642, in press.

Ansorge, C., and J. P. Mellado, 2014: Global intermittency and collapsing turbulence in the stratified planetary boundary layer. Bound.-Layer Meteor., 153, 89-116, https://doi.org/ 10.1007/s10546-014-9941-3.

Baklanov, A. A., and Coauthors, 2011: The nature, theory, and modeling of atmospheric planetary boundary layers. Bull. Amer. Meteor. Soc., 92, 123-128, https://doi.org/10.1175/ 2010BAMS2797.1.

Banta, R. M., Y. L. Pichugina, and W. A. Brewer, 2006: Turbulent velocity-variance profiles in the stable boundary layer generated by a nocturnal low-level jet. J. Atmos. Sci., 63, 2700-2719, https://doi.org/10.1175/JAS3776.1.

_ L. Mahrt, D. Vickers, J. Sun, B. B. Balsley, Y. L. Pichugina, and E. J. Williams, 2007: The very stable boundary layer on nights with weak low-level jets. J. Atmos. Sci., 64, 3068-3090, https://doi.org/10.1175/JAS4002.1.

Barthlott, C., N. Kalthoff, and F. Fiedler, 2003: Influence of highfrequency radiation on turbulence measurements on a $200 \mathrm{~m}$ tower. Meteor. Z, 12, 67-71, https://doi.org/10.1127/0941-2948/ 2003/0012-0067.

Basu, S., F. Porté-agel, E. Foufoula-Georgiou, J.-F. Vinuesa, and M. Pahlow, 2006: Revisiting the local scaling hypothesis in stably stratified atmospheric boundary-layer turbulence: An integration of field and laboratory measurements with largeeddy simulations. Bound.-Layer Meteor., 119, 473-500, https:// doi.org/10.1007/s10546-005-9036-2.

Beeken, A., T. Neumann, and A. Westerhellweg, 2008: Five years of operation of the first offshore wind research platform in the German bight-FINO1. German Wind Energy Institute Tech. Rep., 5 pp., http://www.dewi.de/dewi/fileadmin/pdf/publications/ Publikations/5_Beeken.pdf.

Blumen, W., 1984: An observational study of instability and turbulence in nighttime drainage winds. Bound.-Layer Meteor., 28, 245-269, https://doi.org/10.1007/BF00121307.

—, R. Banta, S. P. Burns, D. C. Fritts, R. Newsom, G. S. Poulos, and J. Sun, 2001: Turbulence statistics of a Kelvin-Helmholtz billow event observed in the night-time boundary layer during the Cooperative Atmosphere-Surface Exchange Study field program. Dyn. Atmos. Oceans, 34, 189-204, https://doi.org/ 10.1016/S0377-0265(01)00067-7.

Bowen, B. M., J. A. Baars, and G. L. Stone, 2000: Nocturnal wind direction shear and its potential impact on pollutant transport. J. Appl. Meteor. Climatol., 39, 437-445, https://doi.org/10.1175/ 1520-0450(2000)039<0437:NWDSAI > 2.0.CO;2.

Brümmer, B., I. Lange, and H. Konow, 2012: Atmospheric boundary layer measurements at the $280 \mathrm{~m}$ high Hamburg weather mast 1995-2011: Mean annual and diurnal cycles. Meteor. Z., 21, 319-335, https://doi.org/10.1127/0941-2948/2012/0338.

Coulter, R. L., and J. C. Doran, 2002: Spatial and temporal occurrences of intermittent turbulence during CASES-99. Bound.-Layer Meteor., 105, 329-349, https://doi.org/10.1023/ A:1019993703820.

Deb Burman, P. K., T. V. Prabha, R. Morrison, and A. Karipot, 2018: A case study of turbulence in the nocturnal boundary layer during the Indian summer monsoon. Bound.-Layer Meteor., 169, 115-138, https://doi.org/10.1007/s10546-018-0364-4.

Derbyshire, S. H., 1999: Boundary-layer decoupling over cold surfaces as a physical boundary-instability. Bound.-Layer Meteor., 90, 297-325, https://doi.org/10.1023/A:1001710014316.

Donda, J. M. M., I. G. S. van Hooijdonk, A. F. Moene, H. J. J. Jonker, G. J. F. van Heijst, H. J. H. Clercx, and B. J. H. van de
Wiel, 2015: Collapse of turbulence in stably stratified channel flow: A transient phenomenon. Quart. J. Roy. Meteor. Soc., 141, 2137-2147, https://doi.org/10.1002/QJ.2511.

Doran, J. C., 2004: Characteristics of intermittent turbulent temperature fluxes in stable conditions. Bound.-Layer Meteor., 112, 241-255, https://doi.org/10.1023/B:BOUN.0000027907.06649.d0.

Dörenkämper, M., B. Witha, G. Steinfeld, D. Heinemann, and M. Kühn, 2015: The impact of stable atmospheric boundary layers on wind-turbine wakes within offshore wind farms. J. Wind Eng. Ind. Aerodyn., 144, 146-153, https://doi.org/ 10.1016/j.jweia.2014.12.011.

Durst, C. S., 1933: The breakdown of steep wind gradients in inversions. Quart. J. Roy. Meteor. Soc., 59, 131-136, https:// doi.org/10.1002/qj.49705924906.

Fischer, J.-G., C. Senet, O. Outzen, A. Schneehorst, and K. Herklotz, 2012: Regional oceanographic distinctions in the south-eastern part of the North Sea: Results of two years of monitoring at the research platforms FINO1 and FINO3. 11th German Wind Energy Conf., Bremen, Germany, DEWI.

Floors, R., A. Peña, and S.-E. Gryning, 2015: The effect of baroclinicity on the wind in the planetary boundary layer. Quart. J. Roy. Meteor. Soc., 141, 619-630, https://doi.org/10.1002/ qj.2386.

Flores, O., and J. J. Riley, 2011: Analysis of turbulence collapse in the stably stratified surface layer using direct numerical simulation. Bound.-Layer Meteor., 139, 241-259, https://doi.org/ 10.1007/S10546-011-9588-2.

Genthon, C., M. S. Town, D. Six, V. Favier, S. Argentini, and A. Pellegrini, 2010: Meteorological atmospheric boundary layer measurements and ECMWF analyses during summer at Dome C, Antarctica. J. Geophys. Res., 115, D05104, https:// doi.org/10.1029/2009JD012741.

— D. Six, H. Gallée, P. Grigioni, and A. Pellegrini, 2013: Two years of atmospheric boundary layer observations on a $45-\mathrm{m}$ tower at Dome C on the Antarctic plateau. J. Geophys. Res. Atmos., 118, 3218-3232, https://doi.org/10.1002/JGRD.50128.

Gifford, F., 1952: The breakdown of a low-level inversion studied by means of detailed soundings with modified radiosonde. Bull. Amer. Meteor. Soc., 33, 373-379, https://doi.org/10.1175/ 1520-0477-33.9.373.

Grachev, A. A., C. W. Fairall, P. O. G. Persson, E. L. Andreas, and P. S. Guest, 2005: Stable boundary-layer scaling regimes: The SHEBA data. Bound.-Layer Meteor., 116, 201-235, https:// doi.org/10.1007/s10546-004-2729-0.

—, E. L. Andreas, C. W. Fairall, P. S. Guest, and P. O. G. Persson, 2008: Turbulent measurements in the stable atmospheric boundary layer during SHEBA: Ten years after. Acta Geophys., 56, 142-166, https://doi.org/10.2478/S11600-0070048-9.

,,,--- , and,- 2013 : The critical Richardson number and limits of applicability of local similarity theory in the stable boundary layer. Bound.-Layer Meteor., 147, 51-82, https://doi.org/10.1007/s10546-012-9771-0.

Grant, A. L. M., 1997: An observational study of the evening transition boundary-layer. Quart. J. Roy. Meteor. Soc., 123, 657-677, https://doi.org/10.1002/qj.49712353907.

Gryning, S.-E., R. Floors, A. Peña, E. Batchvarova, and B. Brümmer, 2016: Weibull wind-speed distribution parameters derived from a combination of wind-lidar and tallmast measurements over land, coastal and marine sites. Bound.-Layer Meteor., 159, 329-348, https://doi.org/10.1007/ s10546-015-0113-x. 
Holdsworth, A. M., T. Rees, and A. H. Monahan, 2016: Parameterization sensitivity and instability characteristics of the maximum sustainable heat flux framework for predicting turbulent collapse. J. Atmos. Sci., 73, 3527-3540, https:// doi.org/10.1175/JAS-D-16-0057.1.

Holtslag, A. A. M., and Coauthors, 2013: Stable atmospheric boundary layers and diurnal cycles: Challenges for weather and climate models. Bull. Amer. Meteor. Soc., 94, 1691-1706, https://doi.org/10.1175/BAMS-D-11-00187.1.

Kaimal, J. C., and J. E. Gaynor, 1983: The Boulder Atmospheric Observatory. J. Appl. Meteor. Climatol., 22, 863-880, https:// doi.org/10.1175/1520-0450(1983)022<0863:TBAO>2.0.CO;2.

Kalthoff, N., and B. Vogel, 1992: Counter-current and channelling effect under stable stratification in the area of Karlsruhe. Theor. Appl. Climatol., 45, 113-126, https://doi.org/10.1007/ BF00866400.

Kohler, M., J. Metzger, and N. Kalthoff, 2018: Trends in temperature and wind speed from 40 years of observations at a $200-\mathrm{m}$ high meteorological tower in southwest Germany. Int. J. Climatol., 38, 23-34, https://doi.org/10.1002/joc.5157.

Kondo, J., O. Kanechika, and N. Yasuda, 1978: Heat and momentum transfers under strong stability in the atmospheric surface layer. J. Atmos. Sci., 35, 1012-1021, https://doi.org/ 10.1175/1520-0469(1978)035<1012:HAMTUS>2.0.CO;2.

Lundquist, J. K., 2003: Intermittent and elliptical inertial oscillations in the atmospheric boundary layer. J. Atmos. Sci., 60, 2661-2673, https://doi.org/10.1175/1520-0469(2003)060<2661: IAEIOI $>2.0 . \mathrm{CO} ; 2$

Mahrt, L., 1998a: Nocturnal boundary-layer regimes. Bound.-Layer Meteor., 88, 255-278, https://doi.org/10.1023/A:1001171313493.

, 1998b: Stratified atmospheric boundary layers and breakdown of models. Theor. Comput. Fluid Phys., 11, 263-279, https://doi.org/10.1007/s001620050093.

- 2010: Common microfronts and other solitary events in the nocturnal boundary layer. Quart. J. Roy. Meteor. Soc., 136, 1712-1722, https://doi.org/10.1002/qj.694.

_ 2011: The near-calm stable boundary layer. Bound.-Layer Meteor., 140, 343-360, https://doi.org/10.1007/s10546-0119616-2.

, 2014: Stably stratified atmospheric boundary layers. Annu. Rev. Fluid Mech., 46, 23-45, https://doi.org/10.1146/annurevfluid-010313-141354.

— conditions. Bound.-Layer Meteor., 119, 19-39, https://doi.org/ 10.1007/s10546-005-9017-5.

—, S. Richardson, N. Seaman, and D. Stauffer, 2012: Turbulence in the nocturnal boundary layer with light and variable winds. Quart. J. Roy. Meteor. Soc., 138, 1430-1439, https://doi.org/ 10.1002/qj.1884.

Mauritsen, T., and G. Svensson, 2007: Observations of stably stratified shear-driven atmospheric turbulence at low and high Richardson numbers. J. Atmos. Sci., 64, 645-655, https:// doi.org/10.1175/JAS3856.1.

Medeiros, L. E., and D. R. Fitzjarrald, 2014: Stable boundary layer in complex terrain. Part I: Linking fluxes and intermittency to an average stability index. J. Appl. Meteor. Climatol., 53, 2196-2215, https://doi.org/10.1175/JAMC-D-13-0345.1.

Monahan, A. H., T. Rees, Y. He, and N. McFarlane, 2015: Multiple regimes of wind, stratification, and turbulence in the stable boundary layer. J. Atmos. Sci., 72, 3178-3198, https://doi.org/ 10.1175/JAS-D-14-0311.1.

Nakamura, R., and L. Mahrt, 2005: A study of intermittent turbulence with CASES-99 tower measurements. Bound.-Layer
Meteor., 114, 367-387, https://doi.org/10.1007/s10546-0040857-1.

Nappo, C. J., 1991: Sporadic breakdowns of stability in the PBL over simple and complex terrain. Bound.-Layer Meteor., 54, 69-87, https://doi.org/10.1007/BF00119413.

Newsom, R. K., and R. M. Banta, 2003: Shear-flow instability in the stable nocturnal boundary layer as observed by Doppler lidar during CASES-99. J. Atmos. Sci., 60, 16-33, https://doi.org/ 10.1175/1520-0469(2003)060<0016:SFIITS >2.0.CO;2.

Ohya, Y., R. Nakamura, and T. Uchida, 2008: Intermittent bursting of turbulence in a stable boundary layer with low-level jet. Bound.-Layer Meteor., 126, 349-363, https://doi.org/10.1007/ s10546-007-9245-y.

Optis, M., and A. Monahan, 2017: A comparison of equilibrium and time-evolving approaches to modeling the wind profile under stable stratification. J. Appl. Meteor. Climatol., 56, 1365-1382, https://doi.org/10.1175/JAMC-D16-0324.1.

,$--\frac{\sim}{-}$, and F. C. Bosveld, 2016: Limitations and breakdown of Monin-Obukhov similarity theory for wind profile extrapolation under stable stratification. Wind Energy, 19, 1053-1072, https://doi.org/10.1002/we.1883.

Pahlow, M., M. B. Parlange, and F. Porté-Agel, 2001: On MoninObukhov similarity in the stable atmospheric boundary layer. Bound.-Layer Meteor., 99, 225-248, https://doi.org/10.1023/ A:1018909000098.

Rabiner, L. R., 1989: A tutorial on hidden Markov models and selected applications in speech recognition. Proc. IEEE, 77, 257-286, https://doi.org/10.1109/5.18626.

Rishel, J., S. Johnson, and D. Holt, 2003: Meteorological monitoring at Los Alamos. Los Alamos National Laboratory Rep. LA-UR-03-9097, 36 pp., https://envweb.lanl.gov/weathermachine/ downloads/LA-UR-03-8097_webcopy.pdf.

Rysman, J.-F., A. Lahellec, E. Vignon, C. Genthon, and S. Verrier, 2016: Characterization of atmospheric Ekman spirals at Dome C, Antarctica. Bound.-Layer Meteor., 160, 363-373, https:// doi.org/10.1007/s10546-016-0144-y.

Samelson, R. M., E. D. Skyllingstad, D. B. Chelton, S. K. Esbensen, L. W. O'Neill, and N. Thum, 2006: On the coupling of wind stress and sea surface temperature. J. Climate, 19, 1557-1566, https://doi.org/10.1175/JCLI3682.1.

Sorbjan, Z., 1986: On similarity in the atmospheric boundary layer. Bound.-Layer Meteor., 34, 377-397, https://doi.org/10.1007/ BF00120989.

Sun, J., and Coauthors, 2002: Intermittent turbulence associated with a density current passage in the stable boundary layer. Bound.-Layer Meteor., 105, 199-219, https://doi.org/10.1023/ A:1019969131774.

— , and Coauthors, 2004: Atmospheric disturbances that generate intermittent turbulence in nocturnal boundary layers. Bound.-Layer Meteor., 110, 255-279, https://doi.org/10.1023/ A:1026097926169.

— L. Mahrt, R. M. Banta, and Y. L. Pichugina, 2012: Turbulence regimes and turbulence intermittency in the stable boundary layer during CASES-99. J. Atmos. Sci., 69, 338-351, https:// doi.org/10.1175/JAS-D-11-082.1.

,,-- C. Nappo, and D. H. Lenschow, 2015: Wind and temperature oscillations generated by wave-turbulence interactions in the stably stratified boundary layer. J. Atmos. Sci., 72, 1484-1503, https://doi.org/10.1175/JAS-D-14-0129.1.

van de Wiel, B. J. H., R. J. Ronda, A. F. Moene, H. A. R. De Bruin, and A. A. M. Holtslag, 2002a: Intermittent turbulence and oscillations in the stable boundary layer over land. Part I: 
A bulk model. J. Atmos. Sci., 59, 942-958, https://doi.org/ 10.1175/1520-0469(2002)059<0942:ITAOIT>2.0.CO;2.

- A. F. Moene, R. J. Ronda, H. A. R. D. Bruin, and A. A. M. Holtslag, 2002b: Intermittent turbulence and oscillations in the stable boundary layer over land. Part II: A system dynamics approach. J. Atmos. Sci., 59, 2567-2581, https://doi.org/ 10.1175/1520-0469(2002)059<2567:ITAOIT $>2.0$. CO 2 .

,,- O. K. Hartogensis, H. A. R. D. Bruin, and A. A. M. Holtslag, 2003: Intermittent turbulence in the stable boundary layer over land. Part III: A classification for observations during CASES-99. J. Atmos. Sci., 60, 2509-2522, https:// doi.org/10.1175/1520-0469(2003)060<2509:ITITSB >2.0.CO;2.

- - G. J. Steeneveld, O. K. Hartogensis, and A. A. M. Holtslag, 2007: Predicting the collapse of turbulence in stably stratified boundary layers. Flow Turbul. Combust., 79, 251274, https://doi.org/10.1007/s10494-007-9094-2.

,-- , and H. J. J. Jonker, 2012a: The cessation of continuous turbulence as precursor of the very stable nocturnal boundary layer. J. Atmos. Sci., 69, 3097-3127, https://doi.org/10.1175/ JAS-D-12-064.1.

,,$---\longrightarrow$ P. Baas, S. Basu, J. M. M. Donda, J. Sun, and A. A. M. Holtslag, 2012b: The minimum wind speed for sustainable turbulence in the nocturnal boundary layer. J. Atmos. Sci., 69, 3116-3127, https://doi.org/10.1175/JAS-D-12-0107.1.

— , and Coauthors, 2017: Regime transitions in near-surface temperature inversions: A conceptual model. J. Atmos. Sci., 74, 1057-1073, https://doi.org/10.1175/JAS-D-16-0180.1.

van Hooijdonk, I. G. S., J. M. M. Donda, H. J. H. Clercx, F. C. Bosveld, and B. J. H. van de Wiel, 2015: Shear capacity as prognostic for nocturnal boundary layer regimes. J. Atmos. Sci., 72, 1518-1532, https://doi.org/10.1175/JASD-14-0140.1.

_- A. F. Moene, M. Scheffer, H. J. H. Clercx, and B. J. H. van de Wiel, 2017: Early warning signals for regime transition in the stable boundary layer: A model study. Bound.-Layer Meteor., 162, 283-306, https://doi.org/10.1007/s10546-0160199-9.
Van Ulden, A. P. V., and J. Wieringa, 1996: Atmospheric boundary layer research at Cabauw. Bound.-Layer Meteor., 78, 39-69, https://doi.org/10.1007/BF00122486.

Vercauteren, N., and R. Klein, 2015: A clustering method to characterize intermittent bursts of turbulence and interaction with submesomotions in the stable boundary layer. J. Atmos. Sci., 72, 1504-1517, https://doi.org/10.1175/JAS-D-14-0115.1.

Vignon, E., C. Genthon, H. Barral, C. Amory, G. Picard, H. Gallée, G. Casasanta, and S. Argentini, 2017a: Momentum- and heatflux parametrization at Dome C, Antarctica: A sensitivity study. Bound.-Layer Meteor., 162, 341-367, https://doi.org/ 10.1007/s10546-016-0192-3.

— , and Coauthors, 2017b: Stable boundary-layer regimes at Dome C, Antarctica: Observation and analysis. Quart. J. Roy. Meteor. Soc., 143, 1241-1253, https://doi.org/10.1002/qj.2998.

Wenzel, A., N. Kalthoff, and V. Horlacher, 1997: On the profiles of wind velocity in the roughness sublayer above a coniferous forest. Bound.-Layer Meteor., 84, 219-230, https://doi.org/ 10.1023/A:1000444911103.

Westerhellweg, A., and T. Neumann, 2012: FINO1 mast correction. DEWI Mag., 40, 60-66.

White, L. D., 2009: Sudden nocturnal warming events in Mississippi. J. Appl. Meteor. Climatol., 48, 758-755, https:// doi.org/10.1175/2008JAMC1971.1.

Williams, A. G., S. Chambers, and A. Griffiths, 2013: Bulk mixing and decoupling of the nocturnal stable boundary layer characterized using a ubiquitous natural tracer. Bound.-Layer Meteor., 149, 381-402, https://doi.org/10.1007/s10546-013-9849-3.

Yus-Díez, J., M. Udina, M. R. Soler, M. Lothon, E. Nilsson, J. Bech, and J. Sun, 2019: Nocturnal boundary layer turbulence regimes analysis during the BLLAST campaign. Atmos. Chem. Phys., 19, 9495-9514, https://doi.org/10.5194/acp-19-9495-2019.

Zilitinkevich, S. S., T. Elperin, N. Kleeorin, I. Rogachevskii, I. Esau, T. Mauritsen, and M. W. Miles, 2008: Turbulence energetics in stably stratified geophysical flows: Strong and weak mixing regimes. Quart. J. Roy. Meteor. Soc., 134, 793-799, https://doi.org/10.1002/qj.264. 